\title{
Evidence for ice particles in the tropical stratosphere from in-situ measurements
}

\author{
M. de Reus ${ }^{1,2, *}$, S. Borrmann ${ }^{1,2}$, A. Bansemer ${ }^{3}$, A. J. Heymsfield ${ }^{3}$, R. Weigel ${ }^{2}$, C. Schiller ${ }^{4}$, V. Mitev ${ }^{5}$, W. Frey ${ }^{2}$, \\ D. Kunkel ${ }^{1,2}$, A. Kürten ${ }^{6}$, J. Curtius ${ }^{6}$, N. M. Sitnikov ${ }^{7}$, A. Ulanovsky ${ }^{7}$, and F. Ravegnani ${ }^{8}$ \\ ${ }^{1}$ Max Planck Institute for Chemistry, Particle Chemistry Department, Mainz, Germany \\ ${ }^{2}$ Institute for Atmospheric Physics, Mainz University, Germany \\ ${ }^{3}$ National Center for Atmospheric Research, Boulder, USA \\ ${ }^{4}$ Institute of Chemistry and Dynamics of the Geosphere, Research Centre Jülich, Germany \\ ${ }^{5}$ Swiss Centre for Electronics and Microtechnology, Neuchâtel, Switzerland \\ ${ }^{6}$ Institute for Atmospheric and Environmental Sciences, Goethe University of Frankfurt, Germany \\ ${ }^{7}$ Central Aerological Observatory, Dolgoprudny, Moskow Region, Russia \\ ${ }^{8}$ Institute of Atmospheric Sciences and Climate, Bologna, Italy \\ * now at: Elementar Analysensysteme GmbH, Hanau, Germany
}

Received: 19 August 2008 - Published in Atmos. Chem. Phys. Discuss.: 14 November 2008

Revised: 26 August 2009 - Accepted: 27 August 2009 - Published: 18 September 2009

\begin{abstract}
In-situ ice crystal size distribution measurements are presented within the tropical troposphere and lower stratosphere. The measurements were performed using a combination of a Forward Scattering Spectrometer Probe (FSSP-100) and a Cloud Imaging Probe (CIP), which were installed on the Russian high altitude research aircraft M55 "Geophysica" during the SCOUT-O ${ }_{3}$ campaign in Darwin, Australia. One of the objectives of the campaign was to characterise the Hector convective system, which appears on an almost daily basis during the pre-monsoon season over the Tiwi Islands, north of Darwin. In total 90 encounters with ice clouds, between 10 and $19 \mathrm{~km}$ altitude were selected from the dataset and were analysed. Six of these encounters were observed in the lower stratosphere, up to $1.4 \mathrm{~km}$ above the local tropopause. Concurrent lidar measurements on board "Geophysica" indicate that these ice clouds were a result of overshooting convection. Large ice crystals, with a maximum dimension up to $400 \mu \mathrm{m}$, were observed in the stratosphere. The stratospheric ice clouds included an ice water content ranging from $7.7 \times 10^{-5}$ to $8.5 \times 10^{-4} \mathrm{~g} \mathrm{~m}^{-3}$ and were observed at ambient relative humidities (with respect to ice) between 75 and 157\%. Three modal lognormal size distributions were fitted to the average size distributions for different potential temperature intervals, showing that the
\end{abstract}

Correspondence to: S. Borrmann (stephan.borrmann@mpic.de) shape of the size distribution of the stratospheric ice clouds are similar to those observed in the upper troposphere.

In the tropical troposphere the effective radius of the ice cloud particles decreases from $100 \mu \mathrm{m}$ at about $10 \mathrm{~km}$ altitude, to $3 \mu \mathrm{m}$ at the tropopause, while the ice water content decreases from 0.04 to $10^{-5} \mathrm{~g} \mathrm{~m}^{-3}$. No clear trend in the number concentration was observed with altitude, due to the thin and inhomogeneous characteristics of the observed cirrus clouds.

The ice water content calculated from the observed ice crystal size distribution is compared to the ice water content derived from two hygrometer instruments. This independent measurement of the ice water content agrees within the combined uncertainty of the instruments for ice water contents exceeding $3 \times 10^{-4} \mathrm{~g} \mathrm{~m}^{-3}$.

Stratospheric residence times, calculated based on gravitational settling, and evaporation rates show that the ice crystals observed in the stratosphere over the Hector storm system had a high potential of humidifying the stratosphere locally.

Utilizing total aerosol number concentration measurements from a four channel condensation particle counter during two separate campaigns, it can be shown that the fraction of ice particles to the number of aerosol particles remaining ranges from 1:300 to 1:30 000 for tropical upper tropospheric ice clouds with ambient temperatures below $-75^{\circ} \mathrm{C}$.

Published by Copernicus Publications on behalf of the European Geosciences Union. 


\section{Introduction}

Cirrus clouds play a significant role in regulating the radiation balance of the Earth-atmosphere system and are, hence, an important component of the Earth's climate system. Cirrus clouds can absorb and reradiate outgoing terrestrial radiation, and thereby act like a greenhouse gas (warming the atmosphere). At the same time, they can reflect incoming solar radiation back to space and cause a cooling of the atmosphere. Which process dominates and, hence, the arithmetic sign of the net radiative forcing of cirrus clouds, appears to be very sensitive to the cloud microphysical and macrophysical properties (Lynch et al., 2002). For example, thin cirrus clouds cause a small but positive radiative forcing at the top of the atmosphere, whereas thick cirrus clouds may cause cooling (Stephens and Webster, 1981).

Cirrus clouds can also alter the chemical composition of the tropopause region by uptake of water and nitric acid (Voigt et al., 2006), while heterogeneous reactions of halogen species on the surface of cirrus particles can affect the ozone budget of the tropopause region (Borrmann et al., 1996; Solomon et al., 1997).

In addition, cirrus clouds are involved in vertical transport as well as hydration and dehydration of airmasses. Cloud droplets, ice particles, aerosols, and water vapour enter the upper free troposphere by convection and are further transported into the stratosphere by a slower radiatively driven ascent, giving the airmass enough time to dehydrate by condensation and subsequent sedimentation of ice particles (Sherwood and Dessler, 2001). Overshooting convection penetrating directly into the stratosphere, however, might hydrate the stratosphere (Chaboureau et al., 2007; Grosvenor et al., 2007; Corti et al., 2008) and thereby contribute to the observed increase in stratospheric water vapour concentrations (Oltmans et al., 2000).

In order to quantify the radiative effect of cirrus clouds and their influence on the water budget and air chemistry, detailed information about their microphysical properties are necessary. Measurements within cirrus clouds show a wide range of particle shapes, sizes, and concentrations (Heymsfield and McFarquhar, 2002; Schiller et al., 2008; Krämer et al., 2009). Below, examples of in-situ cirrus particle size distribution measurements are given at mid-latitudes and in the tropics, in the troposphere as well as in the stratosphere.

During the INCA (INterhemispheric differences in Cirrus properties from Anthropogenic emissions) project, cirrus measurements were performed in the mid-latitudes of the northern and Southern Hemispheres at up to $12 \mathrm{~km}$ in altitude. In the Northern Hemisphere ice crystals were found to be smaller and associated with higher ice crystal number concentrations compared to the Southern Hemisphere. The mean ice crystal concentration was $2.2 \mathrm{~cm}^{-3}$ in the Northern Hemisphere and $1.4 \mathrm{~cm}^{-3}$ in the Southern Hemisphere, with an effective diameter of $36 \mu \mathrm{m}$ and $42 \mu \mathrm{m}$, respectively. No significant differences in the ice water content and ice crystal shape were observed (Gayet et al., 2004). This is in agreement with mid-latitude Northern Hemisphere measurements presented by Ström et al. (1997). They observed a median ice crystal concentration of $2.6 \mathrm{~cm}^{-3}$, while the crystal number distribution peaks at diameters below $10 \mu \mathrm{m}$. However, artefacts by shattering on the inlet in these datasets cannot be excluded.

Size distributions of cirrus clouds in the upper tropical troposphere, exhibiting a pronounced peak at $10 \mu \mathrm{m}$, have been reported by Thomas et al. (2002). They found very thin layers of subvisible cirrus clouds in the outflow of a cumulonimbus cloud, with ice crystal number concentrations ranging between 0.04 and $0.87 \mathrm{~cm}^{-3}$, depending on the exact position within the cirrus layer. McFarquhar et al. (2000) report on a similar thin subvisible cirrus layer over the tropical central Pacific, with a typical ice water content of between $10^{-6}$ and $10^{-4} \mathrm{~g} \mathrm{~m}^{-3}$, maximum ice crystal sizes of between 30 and $140 \mu \mathrm{m}$, and a positive cloud radiative forcing of up to $5 \mathrm{Wm}^{-2}$. In addition, ultrathin tropical tropospheric clouds (UTTC) were observed directly beneath the tropical tropopause, characterised by a very low ice crystal number concentration $\left(0.05 \mathrm{~cm}^{-3}\right)$. The different cirrus clouds reported in this study, all show a peak in the ice crystal number size distribution at about $10 \mu \mathrm{m}$ diameter. These ultrathin tropical tropospheric clouds may exist for many hours as a cloud layer of only 200-300 m thick just a few hundred meters below the tropical cold point tropopause covering up to $10000 \mathrm{~km}^{2}$ (Peter et al., 2003). In-situ measurements of cirriform clouds in the upper tropical troposphere have been reported by Heymsfield (1986), who found ice crystals (trigonal plates and columns) with sizes up to $50 \mu \mathrm{m}$ at temperatures of $-83^{\circ} \mathrm{C}$ and Knollenberg et al. (1993) who found high concentrations of ice crystals $\left(>10 \mathrm{~cm}^{-3}\right)$ in the anvils of tropical convective systems.

Ice crystals have also been observed in the stratosphere. Besides polar stratospheric clouds, which are observed at cold temperatures over the Arctic and Antarctic, ice crystals have been observed in the tropical stratosphere as well. The presence of clouds in the tropical stratosphere has been attributed to overshooting convection (Chaboureau et al., 2007; Grosvenor et al., 2007; Nielsen et al., 2007; Corti et al., 2008).

This paper shows direct evidence from in-situ measurements for the presence of ice crystals in the tropical stratosphere, immediately above a large convective system, indicating direct transport of cloud particles from the troposphere to the stratosphere. Unique in-situ measurements of the cloud particle size distribution ranging from $3 \mu \mathrm{m}$ to $1.5 \mathrm{~mm}$ diameter are presented. In addition, vertical profiles of the total and non-volatile aerosol number concentration are shown and a relationship between the number of measured ice cloud particles with respect to the available aerosol particles larger than $10 \mathrm{~nm}$ is presented. 


\section{Experiment and instrumentation}

\subsection{The SCOUT-O 3 pre-monsoon in Darwin, Australia, 2005}

During November and December 2005 four aircraft were stationed in Darwin, Australia for a combined mission of the $\mathrm{SCOUT}_{-} \mathrm{O}_{3}$ (Stratospheric-Climate Links with Emphasis on the Upper Troposphere and Lower Stratosphere) and ACTIVE (Aerosol and Chemical Transport in Tropical Convection) projects. The main goal of the mission was to investigate the transport and transformation of water vapour, aerosol and trace gases in deep convection. Darwin was chosen as the aircraft base for the mission because of the Hector storm system, which appears on an almost daily basis over the Tiwi Islands, north of Darwin, during the premonsoon season in November and December (Connolly et al., 2006). The storms generated over the islands can reach heights up to $20 \mathrm{~km}$. Hence, Hector events could play an important role in vertical transport of mass and pollutants into the tropical tropopause layer and possibly the lowermost stratosphere. An overview of the objectives, measurement platforms, instrumentation and performed flights during the SCOUT-O 3 /ACTIVE campaign is presented by Vaughan et al. (2008), while the meteorological situation is described in detail by Brunner et al. (2008).

As part of the $\mathrm{SCOUT}_{-} \mathrm{O}_{3}$ project nine flights were performed with the Russian high altitude research aircraft M55 "Geophysica". Ice crystal size distributions were measured onboard the "Geophysica" using two instruments: a modified Particle Measuring Systems (PMS) Forward Scattering Spectrometer Probe (FSSP-100) with Droplet Measurement Technologies (DMT) high speed electronics (SPP-100) and a DMT Cloud Imaging Probe (CIP).

\subsection{Modified FSSP-100 for cloud particle size distribution measurements $(2.7<\mathbf{D p}<31 \mu \mathrm{m})$}

The FSSP-100 measures the forward scattering of single particles within a scattering angle of 4-12 $2^{\circ}$ (Dye and Baumgardner, 1984). Using Mie-calculations, the size of a particle is related to the measured scattering cross section, which implicitly assumes spherical particles. However, for size diameters smaller than $16 \mu \mathrm{m}$ it was shown that the FSSP forward scattering geometry is insensitive towards asphericities for shape aspect ratios larger than 0.5 (Borrmann et al., 2000). Since this study focuses on stratospheric ice crystals, the refractive index of ice has been used. The settings of the instrument during the $\mathrm{SCOUT}-\mathrm{O}_{3}$ project allowed the determination of the ice crystal size distribution in 40 size bins between 2.7 and $31 \mu \mathrm{m}$ diameter (Dp). Due to ambiguities in the Mie scattering curve and the low observed ice crystal number concentrations, the size distributions presented in this paper have been combined into 7 size bins.
The uncertainty of the ice crystal number concentration measured by the FSSP is mainly determined by the uncertainty in the sample volume, which has been estimated to be 20\% (Baumgardner et al., 1992). At low particle number concentrations the uncertainty due to counting statistics has to be taken into account, which is defined as the square root of the number of particles measured. Secondly, it has been recognized that shattering of large ice crystals on the housing of the FSSP and CIP probe may produce large numbers of small particles, which, under certain circumstances, can lead to incorrect measurements of particle size distributions and subsequently derived microphysical properties (McFarquhar et al., 2007). Due to the relatively low ice crystal number concentrations of relatively large ice crystals and the fact that the size of the largest ice crystal did not exceed $500 \mu \mathrm{m}$ in the upper tropical troposphere and lower stratosphere, it is not likely that shattering has significantly influenced the measurements presented in this study. This will be discussed in detail in Sect. 4.2.

For calculating the particle volume and mass concentration, additionally the uncertainty in the particle sizing is important, which is dependent on particle shape, ambiguities in the Mie curve and uncertainties in the refractive index of the particles. Baumgardner et al. (1992) estimated the overall uncertainty of the FSSP volume concentration measurements to be $60 \%$. Uncertainties due to coincidence are not important for the ice clouds analysed in this paper due to the very low ice crystal number concentration.

\subsection{CIP for cloud particle size distribution measurements $(25<\mathbf{D p}<1550 \mu \mathrm{m})$}

The CIP is a two dimensional optical array probe following the initial design from Knollenberg et al. (1970). Two dimensional shadow images of particles are obtained by a linear array of 64 light detectors as they obscure a laser beam at a rate proportional to the airspeed. At $190 \mathrm{~ms}^{-1}$, the typical cruising speed of the Geophysica in the upper troposphere and lower stratosphere, this corresponds to a sampling rate of $7.6 \mathrm{MHz}$ at the $25 \mu \mathrm{m}$ resolution of the CIP. Each sample of the 64 elements is called a slice; up to 128 slices compose a particle image. The resolution of the resulting particle image is $25 \times 25 \mu \mathrm{m}$, leading to a detectable particle size range of $25-1550 \mu \mathrm{m}(62 \times 25 \mu \mathrm{m})$. Due to an underestimation of the airspeed measured by the CIP probe itself, which resulted from an imprecise calibration of the pressure sensor in the pitot tube, the real resolution was $25 \times 35 \mu \mathrm{m}$ during this project. For the particle size calculations this was taken into account and corrected for.

From the recorded images the particle size has been deduced using two different size definitions: the minimum and the maximum dimension. These are defined as the diameter of a circle with the same cross sectional area as the shaded area of the image and the maximum chord length within the 
particle, respectively. For spherical particles, these two diameters are identical.

Incidences of shattering have been removed from the CIP dataset by using a threshold interarrival time of $10^{-5} \mathrm{~s}$ (Field et al., 2006). This method assumes that shattering of a large ice crystal causes a burst of small particles with very short interarrival times, which can be distinguished from the longer interarrival times of real cloud particles in a cirrus cloud.

Particles shading the first or the last diode of the array are removed from the dataset. Since mainly small particles $(\mathrm{Dp}<400 \mu \mathrm{m})$ were observed in this project, this will not lead to a high rejection rate of observed particles. In addition, particles are rejected when the ratio of the shaded area of the particles to the area of a circle with the maximum dimension is below 0.1. This eliminates many bad particles, for example "streakers" which are caused by splash or shatter products travelling slower than the true airspeed through the sample volume. This rejection criterion also removes most of the images containing two particles.

The data acquisition system of the CIP is first started when the diode array detects a shaded diode, which leads to the loss of the first slice of each particle image. This lost leading slice has been reconstructed by duplicating the first recorded slice (i.e. the second slice of the particle image) and then removing a pixel from each edge of this slice, until at least half of the pixels are gone. This reconstructed slice is inserted as slice zero in the image.

Image frames which show no shaded pixels are assumed to have triggered the data acquisition program, but only left a signal in the first, non recorded, slice. These particles are assumed to have a maximum dimension of $43 \mu \mathrm{m}$ ( 1 pixel of $25 \times 35 \mu \mathrm{m})$.

The size of out of focus particles has been corrected according to Korolev et al. (2007). This also includes a correction in the sample volume of the instrument.

Analogous to the FSSP, the uncertainty in the particle number concentration measured with the CIP is mainly determined by the uncertainty in the sample volume and, for low particle concentrations, by counting statistics. The sample volume has been calculated using the entire-in method described by Heymsfield and Parrish (1978). The sample volume increases with increasing particle size, thus compensating for the decrease in concentration with increasing crystal size. The uncertainty in the sample volume is estimated to be $20 \%$, similar as for the FSSP. Additional uncertainty in the sample volume is caused by the relatively high aircraft speed of the Geophysica aircraft (up to $200 \mathrm{~ms}^{-1}$ ), due to the non-zero electronic response time of the CIP instrument (Baumgardner and Korolev, 1997).

In order to calculate the particle size distribution and volume concentration, the uncertainty in the particle size has to be taken into account. The uncertainty in the particle size decreases considerably with particle size and is $\pm 25 \mu \mathrm{m}$ for particles $>50 \mu \mathrm{m}$ diameter. The intensity of the laser light on a diode has to decrease by more than $50 \%$ to be recorded as shadowed. This means that theoretically a $25 \mu \mathrm{m}$ particle which passes exactly over the middle of two diodes will be recorded as a $50 \mu \mathrm{m}$ particle, but also a $74.9 \mu \mathrm{m}$ particle will be interpreted as a $50 \mu \mathrm{m}$ particle when it completely shadows two diodes and partially shadows two more by only $49.8 \%$. For the first particle size bin, with a nominal size of $25 \mu \mathrm{m}$ diameter, particles could have a diameter between 12.5 and $49.9 \mu \mathrm{m}$. The non-zero response time of the photodiodes causes an additional uncertainty in the measured particle size at high airspeed (Strapp et al., 2001). Moreover, the particle diameter derived from the measurements depends on the chosen definition of the particle size. To demonstrate this uncertainty, ice crystal size distributions using the minimum and maximum dimensions of the particle are shown in Fig. 1.

\subsection{Combined number size distributions from the modified FSSP-100 and the CIP}

In this paper data of the FSSP and CIP are combined to attain ice crystal size distributions for particles with a diameter between $3 \mu \mathrm{m}$ to $1.5 \mathrm{~mm}$. Figure 1 shows an example of a combined size distribution which was observed in the stratosphere, $0.7 \mathrm{~km}$ above the local tropopause, over the Tiwi islands on 30 November 2005 (see Sect. 3.3). Additionally, the interarrival time distribution for the ice crystals observed by the CIP is shown for this time period, indicating the different distributions of the ice crystals in natural cirrus clouds and shattered crystal fragments. During the selected time period 3009 ice crystals were recorded by the CIP. From these, 199 particles are rejected based on the interarrival time criterion $(6.6 \%), 15(0.5 \%)$ because their area ratio was smaller than 0.1 and $347(11.5 \%)$ because the shadow image touched one of the end diodes. Note that ice crystal images can be rejected by different criteria at the same time. The ice crystal size distribution measured by the CIP, shown in Fig. 1, is therefore based on a total of 2479 ice crystals, which is $82 \%$ of the total recorded images during this time period. The FSSP counted 938 ice crystals during the same time period, which nevertheless results in higher concentrations than have been observed by the CIP, because of the up to 10 times smaller sample volume of the FSSP compared to the CIP.

A good agreement between the CIP and FSSP in the overlap region was observed during this time period. However, this was not always the case for the measurements during the campaign. Note that the overlap region is very small and the uncertainty of the CIP for particles smaller than $100 \mu \mathrm{m}$ is large due to the relatively large sizing uncertainty for this size range and potential losses of particles with sizes smaller than $100 \mu \mathrm{m}$ (Korolev et al., 1998). A large difference in the size distribution can be observed for the different size definitions. In the remainder of this paper the maximum diameter is used for characterising the size of the ice crystals. The uncertainty in the measured number concentrations, which is displayed in Fig. 1 is the sum of the uncertainty in sample 

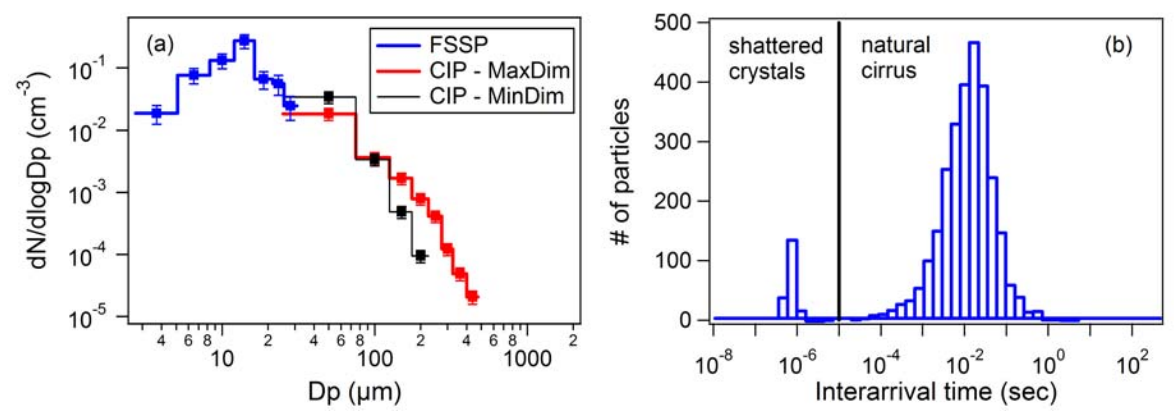

(c)

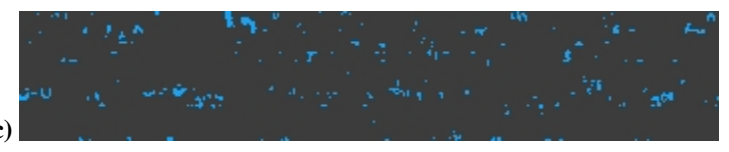

(d)

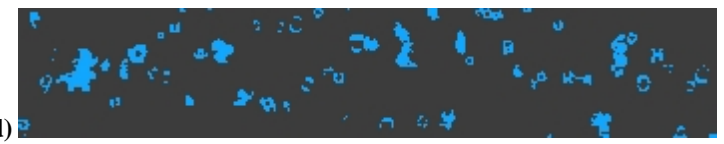

Fig. 1. (a) Ice crystal size distribution observed in the tropical stratosphere, $0.7 \mathrm{~km}$ above the local tropopause, over the Tiwi islands on 30 November 2005 (event 1 in Fig. 6). The ice crystal size distribution has been composed from FSSP and CIP data. For the CIP data the maximum and minimum dimension are shown. (b) Interarrival time distribution for the ice crystals observed by the CIP for this time period, indicating the crystals which are produced by shattering and therefore have been removed from the data set. (c) Ice crystal images recorded by the CIP instrument for this time period. (d) Example of larger ice crystals observed on 28 November 2005 at $10 \mathrm{~km}$ altitude.

volume and counting statistics. For clarity reasons, in other graphs the error bars have been omitted.

From the number size distributions the volume size distribution and total mass (ice water content) can be calculated which is explained in Sect. 3.2.

\subsection{Ice water content determination from hygrometer measurements}

Besides calculating the ice water content from the observed ice crystal size distributions, the ice water content was also measured independently using two hygrometers. The total water content (gas-phase+particulate) has been measured using the Lyman- $\alpha$ hygrometer FISH (Fast In-Situ Hygrometer; Zöger et al., 1999), which is equipped with a forward facing inlet. Ice particles are over-sampled with an enhancement depending on altitude and cruising speed of the aircraft, which has been corrected for. The sampling characteristics of the FISH inlet on the Geophysica research aircraft have been determined by computational fluid dynamics modeling (Krämer and Afchine, 2004). As shown in this publication, the aspiration coefficient (or enhancement factor) of the aircraft inlet increases from its minimum value (i.e. 1-2) for particles with radii smaller than $0.3 \mu \mathrm{m}$ to its maximum value which is typically achieved for particle radii larger than 3-4 $\mu \mathrm{m}$. Since the IWC is mainly determined by particles larger than 3-4 $\mathrm{m}$ in diameter (see Fig. 2) a constant enhancement factor can be applied. For typical Geophysica cruising altitude and speed, the enhancement factor for particles with radii larger than $4 \mu \mathrm{m}$ is 9 (Schiller et al., 2008). The accuracy of the FISH instrument is typically better than $6 \%$ and the precision is $0.2 \mathrm{ppm}$ for water vapour mixing ratios of $3 \mathrm{ppm}$.

The gas phase water vapour content has been measured using the FLASH (FLuorescent Airborne Stratospheric Hygrometer) instrument (Sitnikov et al., 2007), with a measurement accuracy of $8 \%$. The ice water content is determined by subtracting the water vapour content measured by FLASH from the total water content measured by the FISH instrument (see also Schiller et al., 2008).

\subsection{Interstitial particle measurements using the COPAS instrument}

The interstitial aerosol number concentration has been measured using two COndensation PArticle Counter Systems (COPAS). Each COPAS instrument is a two channel aerosol counter designed for automated low pressure measurements of the particle number concentration (Curtius et al., 2005; Weigel et al., 2009). One of the available four channels is heated to $250^{\circ} \mathrm{C}$, causing volatile particles to evaporate (out of the detectable size range of the COPAS instrument) and meaning that only non-volatile particles are counted. The other three channels are not heated but operated with 


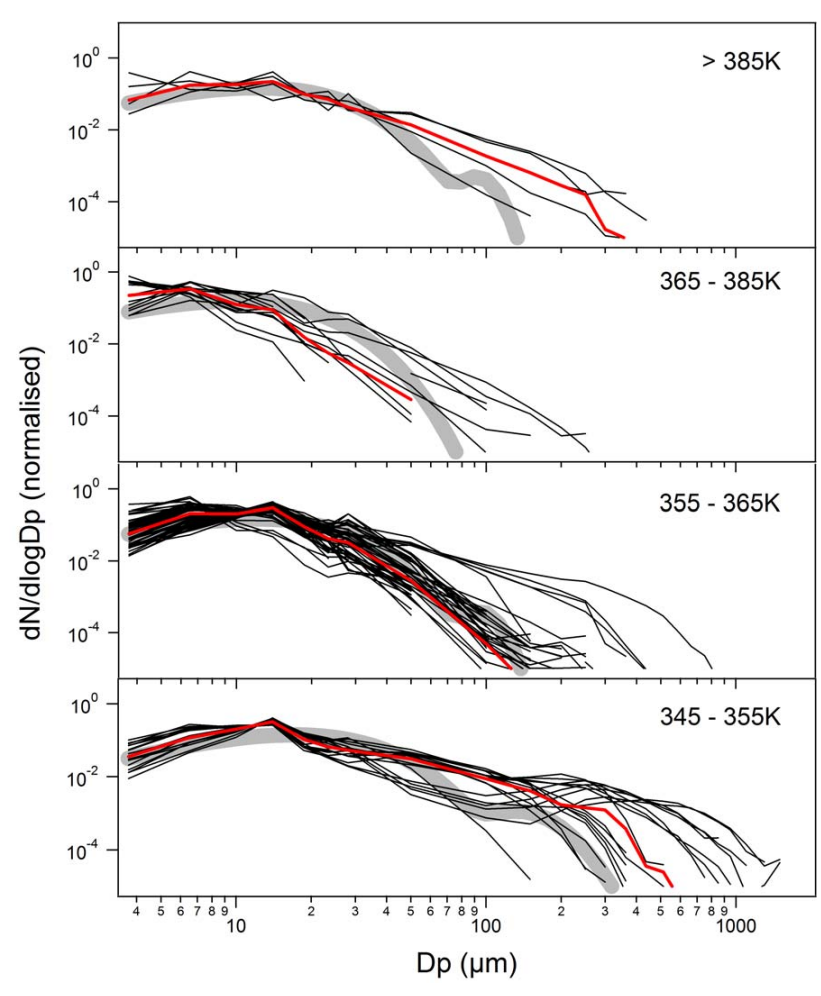

Fig. 2. Normalised ice crystal size distributions of the selected cirrus events (black lines). The median observed size distribution is included as red line. For clarity no error bars are shown here and no information about the overlapping size region of FSSP and CIP. The uncertainties are highlighted for a selected size distribution in Fig. 1. The thick grey line shows the ice crystal size distribution calculated using the parameterisation of McFarquhar and Heymsfield (1997) for the average IWC and ambient temperature in the different potential temperature bins.

different temperature settings, resulting in different $50 \%$ cutoff diameters of 6,10 and $14 \mathrm{~nm}$, respectively. The total aerosol number concentration for particles with diameters larger than 6,10 and $14 \mathrm{~nm}$ is denoted as $\mathrm{N}_{6}, \mathrm{~N}_{10}$ and $\mathrm{N}_{14}$. The $50 \%$ cut off diameter of the heated channel is $10 \mathrm{~nm}$, therefore, the particle number concentration measured by this channel is referred to as $\mathrm{N}_{10 \mathrm{nv}}$. The number concentration of particles with diameters between 6 and $14 \mathrm{~nm}\left(\mathrm{~N}_{6-14}\right)$ has been obtained by subtracting $\mathrm{N}_{14}$ from $\mathrm{N}_{6}$. These particles are so small that they are assumed to be recently formed in the atmosphere by gas to particle conversion processes (Curtius, 2006). They are often called ultrafine or nucleation mode particles.

\subsection{Other instrumentation}

Ozone mixing ratios have been determined using the Fast OZone ANalyzer (FOZAN), which is a chemiluminescence sensor operating with an precision of $0.01 \mathrm{ppm}$ and an accuracy of $8 \%$ (Yushkov et al., 1999). The ambient temperature has been measured using a Thermo Dynamic Complex (TDC) probe with an accuracy of $0.5 \mathrm{~K}$. Other parameters such as position and true air speed have been adopted from the onboard navigational system UCSE (Unified Communications for Systems Engineer) of the "Geophysica" aricraft.

\section{Observations of ice crystals in the outflow of convective clouds}

During the $\mathrm{SCOUT}^{-\mathrm{O}_{3}}$ campaign nine flights were performed with the high altitude research aircraft M55 "Geophysica" from Darwin, Australia. Five flights focussed on in-situ measurements of the Hector storm system, while during the remaining four survey flights remote sensing of water vapour, cirrus, and trace gases was prioritised. During the Hector flights the aircraft did not penetrate the Hector storm system itself, because of aircraft safety reasons, but mainly probed the outflow from the storm system in the upper troposphere and overshooting convection in the lower stratosphere. During the survey flights measurements were performed in cirrus clouds as well, however these were not directly connected to the Hector storm system. The FSSP-100 was operated on all Hector flights and three survey flights, while the CIP provided reliable data on four Hector flights and one survey flight. In this paper we focus on those five flights during which the FSSP and CIP instruments were operated simultaneously, i.e. the flights on 25, 28, 29 and 30 November (double flight), 2005.

Between the selected flights, the tropopause heights (defined by the in-situ measured cold point temperature) ranged in altitude from 16.8 to $18 \mathrm{~km}$, partly because of the vicinity of the strong convective system. This corresponds to a cold point temperature ranging between -84 and $-88^{\circ} \mathrm{C}$ (Brunner et al., 2008).

Within the data sets a cirrus encounter was defined as a time period of at least $30 \mathrm{~s}$ in which particles with sizes beyond the lower detection limit of the FSSP-100 $(2.7 \mu \mathrm{m}$ diameter) were detected at temperatures below $-35^{\circ} \mathrm{C}$. When the aircraft changed altitude, the averaging times were adjusted to ensure that the average was taken over an altitude range not exceeding $1 \mathrm{~km}$. In addition, for longer encounters with cirrus clouds more averages were made so that the maximum averaging time was $430 \mathrm{~s}$. In total 90 cirrus encounters, between 10 and $19 \mathrm{~km}$ altitude, were selected with an average duration of $138 \mathrm{~s}$ (corresponding to a horizontal distance of about $26 \mathrm{~km}$ ).

For each cirrus encounter the ice crystal size distribution has been calculated by combining the data of the FSSP and CIP. To put the observed ice crystal size distribution data in an atmospheric perspective, other parameters (e.g. temperature, pressure, altitude) have been averaged over the same time period. 


\subsection{Ice crystal size distributions}

The ice crystal size distributions (normalised to a total $\mathrm{dN} / \mathrm{d} \log \mathrm{Dp}$ value of 1) of the 90 cirrus encounters are presented in Fig. 2 in potential temperature bins of 10 to 20 degrees. Ice crystals observed at potential temperatures exceeding $385 \mathrm{~K}$ are clearly situated in the stratosphere. The region between 365 and $385 \mathrm{~K}$ is influenced by tropospheric and stratospheric airmasses and is referred to as the tropopause region, while air masses below $365 \mathrm{~K}$ are within the troposphere. From Fig. 2 it is unambiguous that ice crystals have been observed in the stratosphere. The five stratospheric size distributions shown in the upper panel of Fig. 2 are all observed during the first flight on 30 November when the Geophysica aircraft encountered an area with ice crystals in the tropical stratosphere directly over the Hector convective system. A detailed discussion about these stratospheric ice crystals and its origin can be found in Sect. 3.3.

The majority of the ice crystal number size distributions peak between 6 and $15 \mu \mathrm{m}$ diameter. Only $7 \%$ of the distributions show a monotonically decreasing distribution with size, with a maximum number concentration at sizes below $3 \mu \mathrm{m}$ diameter, which could be due to the more recent formation of small ice crystals (Schröder et al., 2000) or sublimation of larger ice crystals. Since we have no additional information about the age of the different ice clouds, this has not been studied in detail. From Fig. 2 it can also be seen that the largest particles, up to $1 \mathrm{~mm}$ maximum dimension, are observed in the lowest potential temperature bin. While ascending to the tropopause region the size of the largest observed ice crystal decreases. Larger particles, with a maximum dimension up to $400 \mu \mathrm{m}$, are observed again in the stratosphere.

In order to learn more about the shape of the size distribution two/three modal lognormal size distributions were fitted to the median normalised size distribution in each potential temperature bin (red lines in Fig. 2). The number concentration, mean mode diameter and standard deviation of each mode describing the lognormal distribution are given in Table 1. When ascending from the lowest level in the troposphere to the tropopause region, the mean mode diameter of the smallest modes shifts to smaller sizes and the largest mode even disappears in the upper troposphere and tropopause region. For example the mean mode diameter of the second mode decreases from $35 \mu \mathrm{m}$ in the middle troposphere to $25 \mu \mathrm{m}$ in the upper troposphere, and $18 \mu \mathrm{m}$ in the tropopause region. The size distributions observed in the stratosphere, however, do not follow this trend, but are similar to the ones observed in the upper troposphere.

Figure 2 also includes normalised ice crystal size distributions calculated according to the cirrus parameterisation reported by McFarquhar and Heymsfield (1997). This parameterisation is based on ice crystal size distribution measurements in cirrus produced as outflows of deep convection made during the Central Equatorial Pacific Experiment
Table 1. Number concentration (N), mean mode diameter (Dp) and standard deviation $(\sigma)$ for the two/three modal lognormal fitted size distributions. Note that the lognormal distribution is fitted to the median normalised size distribution shown in Fig. 2. The number concentration in each mode, however, is then scaled to the median number concentration which is actually observed in the specified potential temperature bin.

\begin{tabular}{lrrr}
\hline & $\mathrm{N}\left(\mathrm{cm}^{-3}\right)$ & $\mathrm{Dp}(\mu \mathrm{m})$ & $\sigma$ \\
\hline$>385 \mathrm{~K}$ & 0.044 & 9 & 1.55 \\
& 0.008 & 25 & 1.55 \\
$365-385 \mathrm{~K}$ & 0.0004 & 65 & 1.75 \\
& 0.074 & 6 & 1.55 \\
$355-365 \mathrm{~K}$ & 0.0009 & 18 & 1.55 \\
& 0.034 & 9 & 1.55 \\
$345-355 \mathrm{~K}$ & 0.0009 & 25 & 1.55 \\
& 0.167 & 10 & 1.55 \\
& 0.026 & 35 & 1.55 \\
& 0.004 & 90 & 1.75 \\
\hline
\end{tabular}

(CEPEX). It is valid for tropical anvil cirrus with an ice water content ranging from $10^{-4}$ to $1 \mathrm{~g} \mathrm{~m}^{-3}$ and an ambient temperature between -20 and $-70^{\circ} \mathrm{C}$. The average ice water content and ambient temperature observed within the potential temperature bins are taken as input for the calculations. The size distributions calculated according to the parameterisation show a similar decrease in ice crystal size with increasing potential temperature in the troposphere, but generally a more pronounced mode at diameters exceeding $100 \mu \mathrm{m}$ is found. Due to the higher ambient temperature in the stratosphere compared to the tropopause region, the largest mode, which is absent in the tropopause region, appears again higher up in the stratosphere, as has been observed in this study. We have to note, however, that the parameterisation is based on size distribution measurements inside tropical cirrus clouds at temperatures down to $-70^{\circ} \mathrm{C}$, while the ambient temperatures in this study were $-53,-80$, -86 , and $-83^{\circ} \mathrm{C}$ for the bottom to the top panel of Fig. 2, respectively. A discussion of the other reported size distributions can be found below.

A two-modal ice crystal size distribution for crystals smaller than $60 \mu \mathrm{m}$ diameter has also been retrieved from satellite measurements in a cirrus cloud associated with a tropical convective system (Eremenko et al., 2005). These measurements show a bimodal size distribution with a pronounced second mode at altitudes exceeding $15 \mathrm{~km}$. The smaller mode peaks at about $6 \mu \mathrm{m}$ diameter and the larger mode at 20-40 $\mu \mathrm{m}$ diameter, comparable to the distributions shown in this study. The existence of a third mode could not be confirmed due to the fact that only particles with diameters $<60 \mu \mathrm{m}$ diameter can be retrieved from this satellite measurement. Model calculations with a one dimensional microphysical model by Chen et al. (1997) for a precipitating anvil 


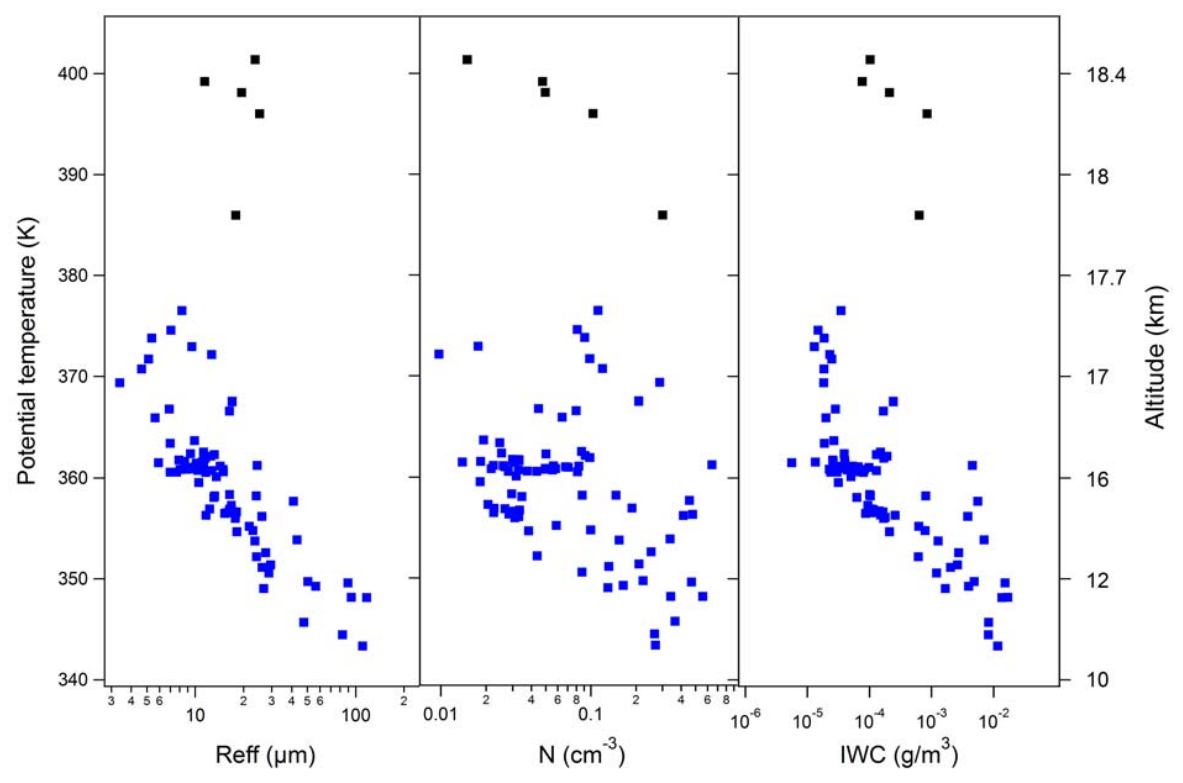

Fig. 3. The effective radius (Reff), ice crystal number concentration (N) and ice water content (IWC) calculated from the ice crystals size distribution presented in Fig. 2. The black markers indicate the ice crystals observed in the stratosphere above the Hector storm system. On the right axis the approximate altitude is shown corresponding to the potential temperature on the left axis.

show a tri-modal cloud particle size distribution. The smallest particles, with a modal value around $10 \mu \mathrm{m}$ diameter, originate mainly from frozen interstitial haze drops, which normally do not freeze until the temperature decreases below $-40^{\circ} \mathrm{C}$. The medium sized particles $(100 \mu \mathrm{m})$ are mainly from frozen cloud drops and the largest particles $(1 \mathrm{~mm})$ mainly from crystal aggregates and rimed ice (Chen et al., 1997). In our study three modes were observed with a mean mode diameter below $100 \mu \mathrm{m}$, indicating a more complicated freezing process or different initial aerosol size distribution. The larger mode has not been observed in our measurements possibly because the ice crystal size distributions presented in this study are mainly observed in the (detached) anvil of the Hector convective system and not directly in the Hector system itself where precipitation could occur.

\subsection{Effective radius and ice water content}

From the observed size distributions several parameters have been deduced, among them the effective radius, the ice crystal number concentration and the ice water content, which are shown in Fig. 3 as a function of the potential temperature.

The effective radius (defined as the ratio of the third to the second moment of a size distribution, in terms of spheres of equivalent cross-section area; McFarquar and Heymsfield, 1998) is one of the key variables that are used for the calculation of the radiative properties of clouds, since it is proportional to the ratio of the ice water content and the extinction coefficient (Heymsfield et al., 2006). For the selected tropospheric cirrus events the effective radius ranges from 3 to $100 \mu \mathrm{m}$ and decreases with increasing potential temperature, altitude and decreasing ambient temperature. This can be explained by preferential lofting of the smaller ice crystals in the updraft of large convective cells. The observation of a decreasing effective radius with altitude is in agreement with observations and model calculations in the tropics presented by Chen et al. (1997), who show a decreasing effective radius with altitude. Also Garrett et al. (2003) observed a decreasing effective radius with decreasing ambient temperature in the sub-tropics. They suggest that this is caused by the fact that homogeneous ice nucleation favours smaller ice crystals at colder temperatures, due to the exponential dependence of the saturation vapour pressure over ice on temperature (Kärcher and Lohmann, 2002), rather than the effect of ageing of the cirrus cloud or gravitational settling.

The observed total ice crystal number concentration was low. Within the cirrus clouds it ranged between 0.01 and $0.7 \mathrm{~cm}^{-3}$ and shows no clear correlation with potential temperature, although the highest ice crystal number concentrations are found at lower altitudes. Note here that for the thin and patchy cirrus clouds observed in this study the ice crystal number concentration depends very much on the position of the aircraft within the cloud and the chosen averaging times.

The ice water content has been calculated from the observed ice crystal size distribution using the algorithm proposed by Baker and Lawson (2006). They performed a linear regression analysis on the logarithms of the data of a 2-dimensional imaging probe to estimate an average mass (M) to area (A) relation of the form $\mathrm{M}=\alpha \mathrm{A}^{\beta}$. They found $\alpha$ to be 0.115 and $\beta$ to be 1.218 , independent of the particle 
habit. This method is not applicable for the FSSP data, since this instrument determines the size of ice crystals based on a completely different principle. Therefore, ice crystals in the FSSP size range are assumed to be solid ice spheres with a density of $0.917 \mathrm{~g} \mathrm{~cm}^{-3}$. The uncertainty in the resulting IWC has been estimated to be a factor 2 (Heymsfield, 2007).

Following the fact that smaller particles were observed with increasing potential temperature in the troposphere, the IWC is also found to decrease with increasing potential temperature. In the upper troposphere an IWC of $10^{-5} \mathrm{~g} \mathrm{~m}^{-3}$ was observed, increasing to $10^{-2} \mathrm{~g} \mathrm{~m}^{-3}$ at $340 \mathrm{~K}$, while values between $10^{-3}$ and $10^{-4} \mathrm{~g} \mathrm{~m}^{-3}$ were found in the stratosphere. A gradual decrease in ice water content with decreasing ambient temperature has also been observed by McFarquhar and Heymsfield (1997) in a tropical area at temperatures between $-20^{\circ} \mathrm{C}$ and $-70^{\circ} \mathrm{C}$, and by Schiller et al. (2008) for a dataset containing polar, mid-latitude and tropical cirrus clouds at temperatures ranging from $-23^{\circ} \mathrm{C}$ to $-90^{\circ} \mathrm{C}$. Note that the observed IWC is much lower than the values reported by Knollenberg et al. (1993) over the same area and corresponding altitudes but during the monsoon season. These measurements were performed during the STEP Tropical Experiment at Darwin in January/February 1987.

The ice water content calculated from the ice crystal size distributions has been compared with the ice water content determined from the two hygrometers (FISH and FLASH) and is shown in Fig. 4. The total uncertainty in the derivation of the IWC from the two hygrometer instruments is estimated to be $20 \%$. It is dependent on the exact position of the inlets of the hygrometers, the calculated enhancement factor of the FISH and the measurement uncertainty of the individual instruments. For the IWC intercomparison hygrometer data for three flights on 29 and 30 November (two flights) are used. These data were also included in the evaluation of the ice water content in Arctic, mid-latitude and tropical cirrus reported by Schiller et al. (2008).

The data for the IWC derived using these two very different methods show a close correspondence over a range of almost three orders of magnitude. The values lie, however, not exactly on the 1:1 agreement line. In air masses with a low IWC the hygrometer data attain higher values than the IWC calculated from the ice crystal size distributions. At larger IWC, the two measurements seem to agree much better. Considering the entire dataset shown in Fig. 4, 97\% of the data points lie within a factor of four of the 1:1 line. For ice water contents exceeding $3 \times 10^{-4} \mathrm{~g} \mathrm{~m}^{-3}$ the IWC determined by the two very different measurement methods agree within the combined uncertainty of the instruments (i.e. a factor of 2.2 as indicated by the thin solid lines in Fig. 4). At low IWC, the ice crystal size distribution mainly consists of small particles, so that the FSSP size range contributes more than $50 \%$ to the observed IWC (see red markers in Fig. 4). Here, the IWC is underestimated by the microphysical measurements, indicating that shattering is not a problem for the microphysical probes at these low IWCs, since in the case

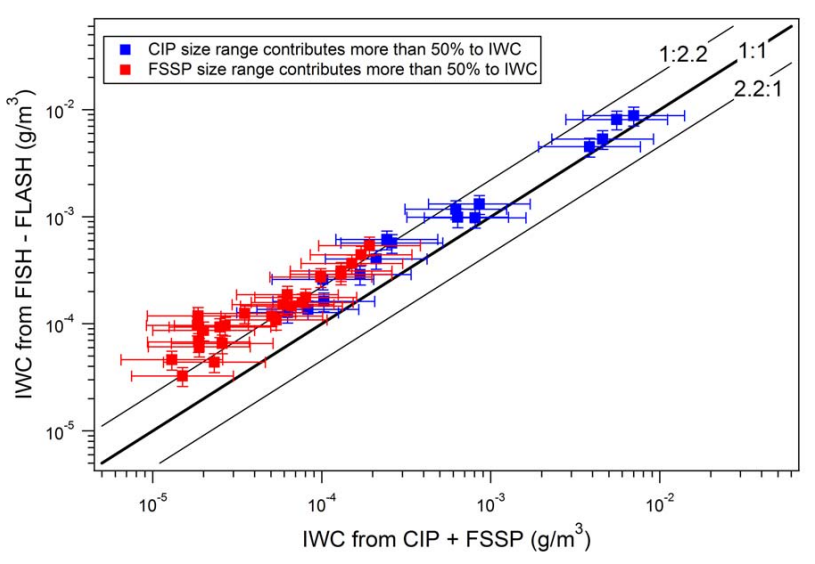

Fig. 4. Comparison of the ice water content derived from the size distribution measurements to the IWC obtained from the hygrometer instruments. The thin solid lines represent a deviation from the 1:1 line (thick solid line) with a factor 2.2, which corresponds to the combined uncertainty of both methods. The data points are averages over at least $30 \mathrm{~s}$ and correspond to the ice cloud encounters on 29 November and the two flights of 30 November from Fig. 3.

of shattering the IWC as derived from the FSSP should have been overestimated. Since the discrepancy between hygrometer IWC and size distribution IWC appears mainly at low IWC, where the IWC is determined by the size range of the FSSP, the main problem nevertheless might be inherent in the FSSP measurements. In this case, the ice crystal number concentration is underestimated by the FSSP, probably due to an uncertainty of the FSSP sample volume. Also it should be kept in mind that the lower size detection limit of the FSSP was set to $3 \mu \mathrm{m}$ and that smaller ice particles may well contribute significantly at very low IWC. We can, however, not exclude that the hygrometers have a larger uncertainty in this IWC range because at these low IWC values two large numbers of the same order of magnitude are subtracted for its calculation.

\subsection{Ice crystals in the stratosphere}

On 30 November 2005 a flight was performed to investigate the Hector convective system. The flight track of this flight is shown in Fig. 5. A large part of the flight was conducted in the stratosphere above the Hector system. According to the pilot's report the aircraft succeeded to pass there through a visible hazy area twice. From the FSSP data six time periods could be selected during which ice crystals were observed for at least $30 \mathrm{~s}$. Unfortunately, CIP data during one time period (No. 5) was lost during the disc write cycles. The ice crystal size distributions of the five remaining time periods are shown in Fig. 2 (top panel), while the parameters characterising the ice crystal size distribution and the meteorological situation are summarised in Table 2. Moreover, in Fig. 6a the time series of temperature, altitude, ice crystal 
Table 2. Average values of different meteorological variables and parameters derived from the ice crystal size distribution during the time periods in which ice crystals were observed in the stratosphere on 30 November (the number of the event corresponds to the number shown in Fig. 6).

\begin{tabular}{lrrrrrr}
\hline & 1 & 2 & 3 & 4 & 5 & 6 \\
\hline Altitude $(\mathrm{km})$ & 18.0 & 18.0 & 18.4 & 18.4 & 18.7 & 18.2 \\
Temperature $\left({ }^{\circ} \mathrm{C}\right)$ & -81.7 & -87.1 & -83.9 & -84.1 & -80.9 & -83.2 \\
Pressure $(\mathrm{hPa})$ & 78.3 & 77.6 & 72.1 & 72.8 & 68.3 & 74.8 \\
Pot. Temp. $(\mathrm{K})$ & 396 & 386 & 401 & 399 & 414 & 398 \\
$\mathrm{RHi}(\%)$ & 76 & 157 & 95 & 107 & 75 & 89 \\
$\mathrm{~N}\left(\mathrm{~cm}^{-3}\right)$ & 0.10 & 0.30 & 0.015 & 0.048 & - & 0.050 \\
$\mathrm{IWC}^{1}\left(\mu \mathrm{g} \mathrm{L}^{-1}\right)$ & 0.85 & 0.64 & 0.10 & 0.077 & - & 0.21 \\
$\mathrm{IWC}^{2}\left(\mu \mathrm{g} \mathrm{L}^{-1}\right)$ & 1.3 & 0.99 & 0.16 & 0.16 & 0.072 & 0.40 \\
$\operatorname{Reff}_{(\mu \mathrm{m})}$ & 25.3 & 17.9 & 23.6 & 11.5 & - & 19.5 \\
Rmean $(\mu \mathrm{m})$ & 9.3 & 4.6 & 7.7 & 5.1 & - & 7.1 \\
\hline
\end{tabular}

${ }^{1}$ IWC derived from the observed ice crystal size distribution.

2 IWC derived from the two hygrometer measurements.

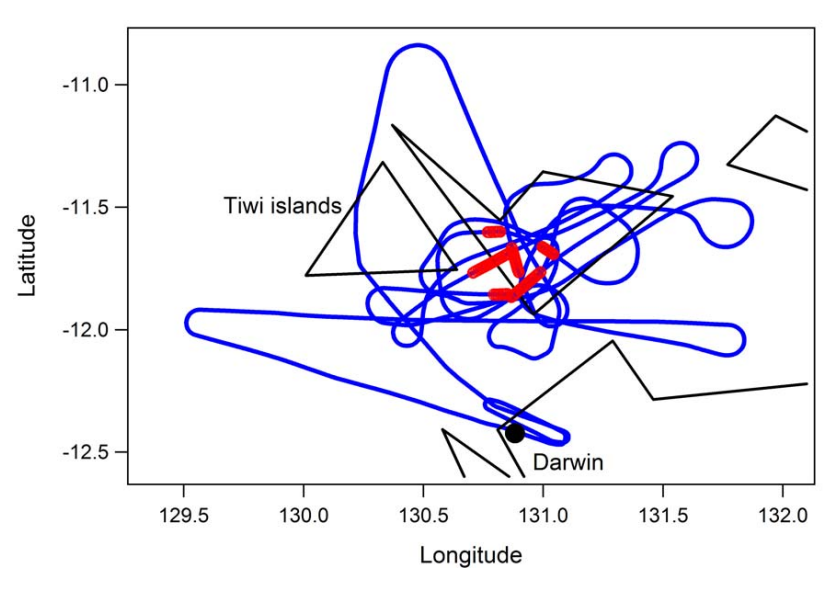

Fig. 5. Flight track of the M55-Geophysica on 30 November 2005. The red symbols indicate the geographical position where the ice crystals were observed in the stratosphere.

number concentration, relative humidity, ozone mixing ratio and total water content for the stratospheric part of the flight on 30 November 2005 are shown. In this figure the selected time periods are shaded and the events are numbered.

Finally Fig. 6b shows the vertical profile of aerosol and cloud particles below the aircraft, as observed by a downward looking Miniature Aerosol Lidar (MAL), which allows observations as close as $160 \mathrm{~m}$ from the aircraft (Mitev et al., 2002; Corti et al., 2008).

The ice crystals were observed at altitudes between 18 and $18.7 \mathrm{~km}$, at temperatures between -81 to $-87^{\circ} \mathrm{C}$ and pressures ranging from 68 to $78 \mathrm{hPa}$, which corresponds to a potential temperature level between 386 and $414 \mathrm{~K}$. The cold point tropopause was situated at $17.3 \mathrm{~km}$ altitude during this day, hence, the ice crystals were observed between 0.7 to $1.4 \mathrm{~km}$ above the tropopause. During four events the air was sub-saturated with respect to ice (RHi varied between 75 and 95\}) indicating a cloud in its decaying state. The remaining two time periods ( 2 and 4 ) show a supersaturation, with an average relative humidity over ice of $107 \%$ and $157 \%$, respectively, which indicates either recent ice crystal formation or direct injection of troposperic ice crystals by recent updraft from the troposphere.

The ice crystal size distribution can be characterised by the effective radius Reff (i.e. the area weighted mean radius of the ice particles), or by the geometric mean radius Rmean (i.e. the number weighted mean size radius). During the five selected time periods, Reff ranged between 12 and $25 \mu \mathrm{m}$ and Rmean between 4.6 and $9.3 \mu \mathrm{m}$. The ice water content calculated from the observed ice crystal size distribution varied between $7.7 \times 10^{-5}$ and $8.5 \times 10^{-4} \mathrm{~g} \mathrm{~m}^{-3}$ and was within a factor of two from the IWC derived from the two hygrometers. Note that the observed IWC are larger by several orders of magnitude than those of the climatology at these low temperatures (Schiller et al., 2008).

By looking at Fig. 6a closely it can be seen that for events 2, 3 and 4, the increase in ice crystal number concentration corresponds with a decrease in $\mathrm{O}_{3}$ mixing ratio and temperature, which is indicative for updraft of tropospheric air into the stratosphere. Moreover, backscatter ratio profiles observed by the lidar on board show remnants of a convective system directly below the aircraft at times when the large total water mixing ratios and high ice crystal number concentrations were observed in the stratosphere. Corti et al. (2008) investigated one of the events in detail and found that the observed IWC was much too high to be formed in-situ. Hence, the ice crystals in the stratosphere likely result from overshooting convection of the Hector system. 

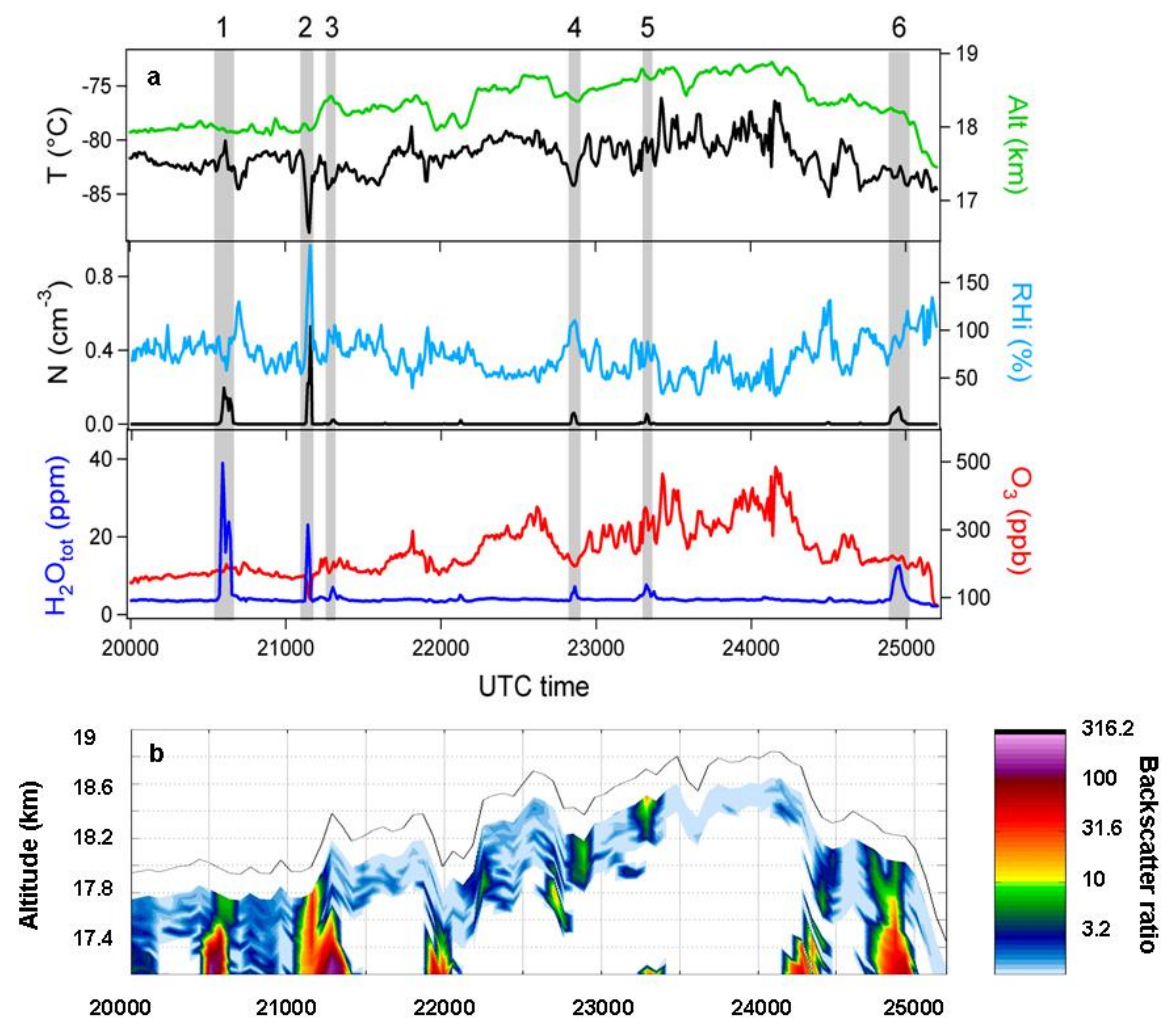

Fig. 6. (a) Ten second averaged values of the temperature, altitude, relative humidity, ice crystal number concentration (N), total water content $\left(\mathrm{H}_{2} \mathrm{O}_{\text {tot }}\right)$ and $\mathrm{O}_{3}$ mixing ratio during the stratospheric part of the flight on 30 November 2005. (b) Backscatter ratio below the aircraft as measured by the downward looking lidar MAL. The black solid curve is the flight altitude. Note that the local tropopause was situated at $17.3 \mathrm{~km}$ altitude on 30 November 2005, which corresponds to the bottom of graph $6 \mathrm{~b}$.

The other events do not show a clear tropospheric signature, which might be a result of mixing of tropospheric and stratospheric air. Another possible explanation for the missing tropospheric signature in these air parcels might be that the ice crystals are formed in-situ in the stratosphere analogous to a pileus cloud. This can be excluded here, because the observed ice crystals are much too large and the observed total ice water content is much too high for in-situ ice formation. Garrett et al. (2006), for example, show a pileus cloud with effective radii between 2 and $4 \mu \mathrm{m}$. However, also during these time periods indicated in Fig. 6 the lidar shows ice crystals down to the local tropopause, indicating overshooting convection as source for the ice crystals.

The terminal settling velocities of the ice crystals observed in the stratosphere have been calculated after Mitchell and Heymsfield (2005) in order to determine their residence times in the stratosphere and thereby their potential for humidifying the stratosphere. Note that for these calculations the size of the ice crystals is kept constant which implies that the reduction in size of the ice crystals by sublimation has not been taken into account. Figure 7 shows the stratospheric residence times for the ice crystal sizes based on gravitational settling only and for those sizes observed during event 1 in Fig. 6. As vertical travelling distance the height above the tropopause (i.e. $0.7 \mathrm{~km}$ for event 1) was used. The gravitational settling velocity ranges from $0.001 \mathrm{~cm} \mathrm{~s}^{-1}$ for ice crystals with a size of $3.7 \mu \mathrm{m}$ to $54 \mathrm{~cm} \mathrm{~s}^{-1}$ for $438 \mu \mathrm{m}$ sized particles. Consequently, the residence time ranges from $0.5 \mathrm{~h}$ to several days.

In order to make an estimate of the ice water which will evaporate within the stratosphere, evaporation times of ice crystals of a certain size have been calculated according to Pratte et al. (2006), using the observed temperature and RHi as input values. They determined evaporation rates of ice crystals at upper tropospheric temperatures from laboratory measurements using a Knudsen flow reactor, resulting in lower values than those given in the literature. Therefore, we used the minimum and maximum rate reported by Pratte et al. (2006) to calculate a range of evaporation times (grey area in Fig. 7). The given range of evaporation rates leads to a large range of evaporation times. For example, $150 \mu \mathrm{m}$ ice crystals would evaporate within one hour using the fast evaporation rate or one day using the slow evaporation rate.

From Fig. 7 it can be seen that even at the lowest evaporation rate all ice crystals smaller than $50 \mu \mathrm{m}$ will evaporate within the stratosphere, corresponding to an IWC of $0.66 \mu \mathrm{g} \mathrm{L}^{-1}$, which is $77 \%$ of the total IWC measured during this event. For the highest evaporation rate even $92 \%$ 


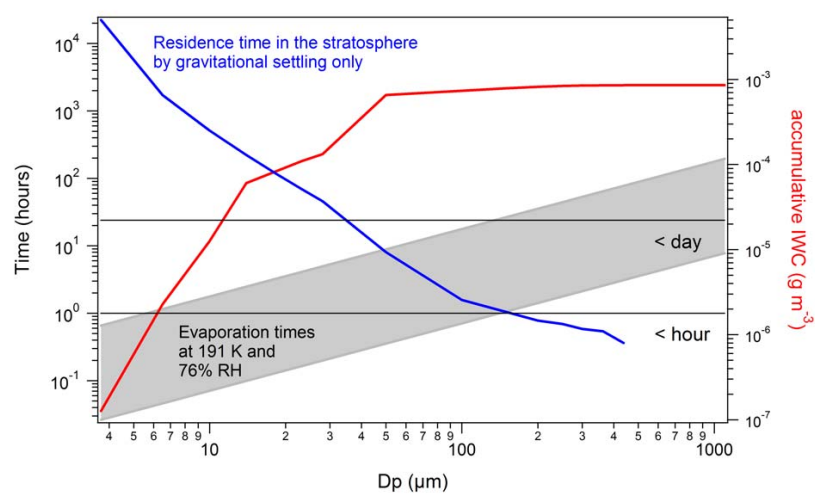

Fig. 7. Evaporation (grey area) and stratospheric residence times (blue line) for the ice crystals observed in event 1 of Fig. 6 assuming that the ice crystals occurred $0.7 \mathrm{~km}$ above the local tropopause. The accumulated ice water content calculated from the measured ice crystal size distribution is given as red solid line on the right axis.

of the ice will evaporate in the stratosphere. For the other stratospheric ice clouds which were found in a subsaturated environment 47-92\% (event 3) and 40-95\% (event 6) of the total IWC will evaporate in the stratosphere.

The amount of ice evaporating in the stratosphere calculated above constitutes a lower limit, since by mixing of air masses the relative humidity of the air parcel containing the ice crystals will diminish leading to faster evaporation. By evaporation the size of the ice crystals will decrease, which reduces their fall speed and hence increases their stratospheric residence time.

The shape of small particles $(<100 \mu \mathrm{m})$ cannot be determined from the CIP images, since they simply consist of too few pixels. The shape of the larger particles observed in the stratosphere, however, has been investigated qualitatively. They were mainly aggregates and columns. Spherical objects were not observed, which indicates that large frozen droplets from the main updraft were not carried into the stratosphere in significant numbers. Detailed modelling of the cloud microphysics of such cumulonimbus clouds is required in order to assess the kinds of crystal habits expected to occur in overshoots.

\subsection{Interstitial aerosols}

The aerosol number concentrations measured with the COPAS instrument during the five investigated flights are shown in Fig. 8. The number concentrations of the interstitial aerosol consisting of non-activated particles in between the ice crystals are presented as coloured dots, while the grey dots present the particle concentrations measured in clear, cloud and ice particle free air parcels, mainly in the vicinity of the cloud. Hence, the coloured dots show the aerosol number concentration during time periods where the FSSP instrument did detect ice crystals, while the grey dots present time periods where the FSSP did not detect any ice crystals.

The total aerosol number concentration for particle sizes larger than $14 \mathrm{~nm}\left(\mathrm{~N}_{14}\right)$ decreases with increasing potential temperature from about $200 \mathrm{~cm}^{-3}$ at $355 \mathrm{~K}$ to less than $20 \mathrm{~cm}^{-3}$ at $435 \mathrm{~K}$. At the same time, the number concentration of non volatile aerosols $\left(\mathrm{N}_{10 \mathrm{nv}}\right)$ decreases from $100 \mathrm{~cm}^{-3}$ to $10 \mathrm{~cm}^{-3}$. Since no information about the aerosol number concentration in the boundary layer is available, no statement can be made about possible enhanced particle concentrations in the outflow region of convective clouds, as has been observed by de Reus et al. (2001) over the northern Indian Ocean. Ultrafine particles $\left(\mathrm{N}_{6-14}\right)$ are mainly observed in the troposphere, with concentrations ranging from 10 to more than $1000 \mathrm{~cm}^{-3}$. Particles from primary sources, such as soot from aircraft emissions, mineral dust or primary biological material, are normally larger in size (Seinfeld and Pandis, 2006). Furthermore, the formation of these small particles must have been recent because nucleation mode particles exist typically only for a few hours to one day, since the aerosols grow by condensation and are lost by coagulation with larger particles (Curtius, 2006). A likely place for the formation of the ultrafine particles is in the outflow of the Hector storm system, because this region is particularly favourable for new particle formation due to the relatively high precursor gas concentrations transported from the lower troposphere, a low pre-existing particle surface area due to the scavenging by large particles inside the cloud and the low ambient temperature in the outflow region (de Reus et al., 2001). Therefore, it is unlikely that the particles were transported aloft directly from the boundary layer within the Hector system and they probably have been formed in-situ in the outflow. This, however, needs confirmation by suitable model calculations.

The presence of ultrafine particles in the stratospheric ice clouds might indicate recent new particle formation, although the observed number concentrations are low compared to earlier observations of new particle formation in tropical cirrus clouds (Lee et al., 2004).

To investigate the aerosol concentrations inside and outside of clouds in detail, probability density functions of the total aerosol number concentration $\left(\mathrm{N}_{14}\right)$ are shown in Fig. 9. In the upper troposphere $(365 \mathrm{~K}-386 \mathrm{~K})$ the $\mathrm{N}_{14}$ concentrations in and out of clouds show similar distributions, although somewhat higher aerosol concentrations were observed in clear air compared to inside clouds. This might show the influence of scavenging within the clouds. In the stratosphere ( $>385 \mathrm{~K})$, mainly concentrations below $200 \mathrm{~cm}^{-3}$ were observed. However, a few occasions of higher aerosol concentrations were found for both in and out of clouds. These high concentrations mainly occurred during the flights on 25 and 30 November and were observed by all four CPC channels of the two independent COPAS instruments. Weigel et al. (2008) identified the plumes on 25 November as crossings of the Geophysica's 


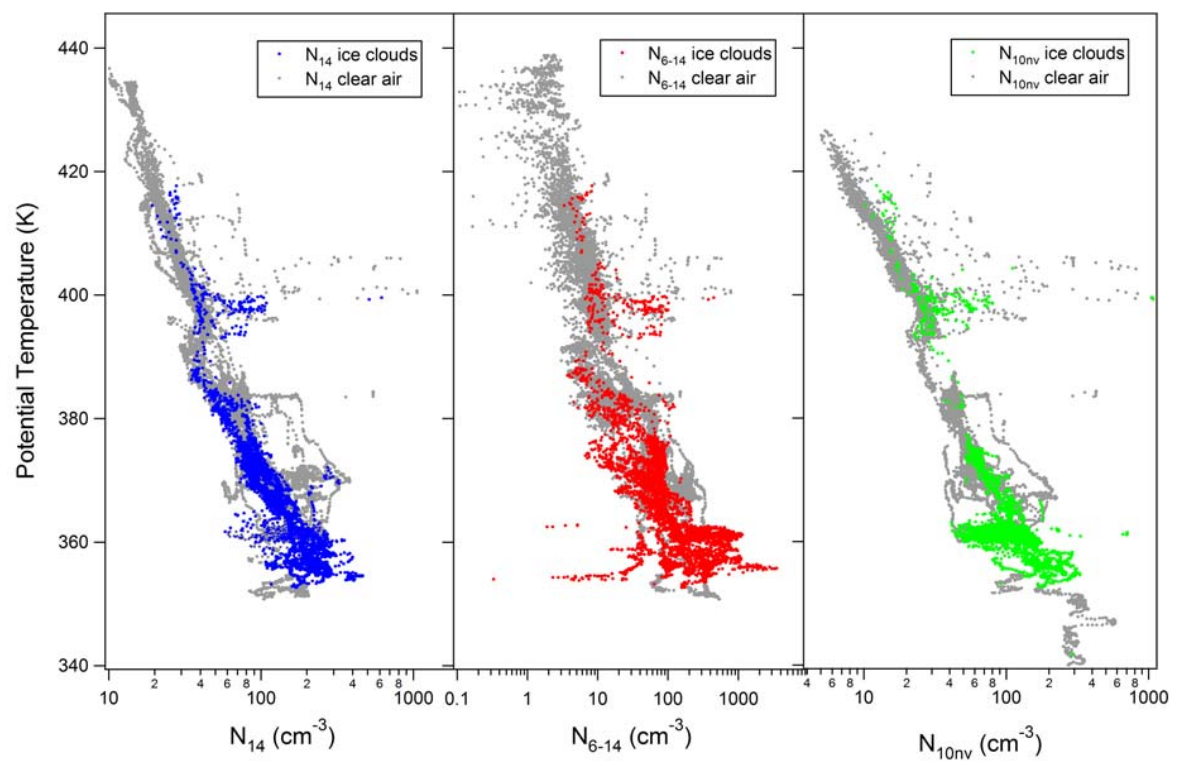

Fig. 8. Profiles of the total, ultrafine and non-volatile aerosol number concentration for in (coloured dots) and out of cloud (grey dots) measurements.

own exhaust, as the short peaks in the particle number concentration occurred simultaneously with peaks in the nitrogen oxide mixing ratio. Unfortunately, for 30 November, no nitrogen oxide measurements are available and the origin of the high particle number concentrations in the stratosphere can only be guessed. They might originate from volcanic eruptions, contrail crossings, or from the updraft of aerosol from the troposphere in overshooting convection. Note that after the evaporation of ice crystals in overshooting convection, higher aerosol concentrations originating from the troposphere might prevail in clear air samples as well.

In the potential temperature range between 345 and $365 \mathrm{~K}$ higher aerosol concentrations were found within clouds compared to out of cloud measurements, which shows the influence of the convective system. Higher aerosol concentrations are lifted up from the boundary layer within the clouds, whereas due to the lack of significant outflow of the convective system in the middle troposphere, the clear air samples show relatively low aerosol concentrations at these altitudes (de Reus et al., 2001).

In Fig. 10 the relation between the interstitial particle number concentration and ice crystal number concentration is shown. The idea behind this plot was to find out how many aerosol particles out of the measured total number of available particles would end up as cloud ice particles. By means of the three lines presented in Fig. 10 one can see that the ratio between interstitial aerosol and ice crystals number densities ranges from 1:300 to 1:30000 in the data sets from Australia in 2005 and West Africa (AMMA-SCOUT-O 3 , Burkina Faso, August 2006). The data from the AMMA-SCOUT-O campaign has been added here to show the range of ratios in tropical ice clouds under other conditions. During the AMMA-SCOUT-O 3 campaign, which was performed during the summer over the North African continent, ice clouds in the upper troposphere were mainly observed in the outflow of large mesoscale convective systems (MSC). In both campaigns, during which the same instrumentation and aircraft was employed, a similar range of ratios was observed. Ratios, as high as one ice crystal per a few hundred remaining aerosol particles were observed within tropical ice clouds. However, it is difficult to determine the degree of activation that occurred with these clouds as there are may factors that could affect this ratio as the air parcel ages, such as removal of aerosol by washout, mixing with the local ambient air and with entrained air, that might contain differing levels of aerosol. Also the ice could have been formed through a variety of processes that are not related to heterogeneous aerosol ice activation, such as homogeneous droplet freezing.

Seifert et al. (2004) investigated the relation between the interstitial particle number concentration and the ice crystal number concentration for mid-latitude cirrus clouds in the Northern and Southern Hemisphere. The observations which are the basis of this analysis were performed during the two INCA (Interhemispheric differences in cirrus properties from anthropogenic emissions) campaigns. They found that the number concentrations of interstitial aerosols and ice crystals were positively related at low interstitial number concentrations $\left(<100 \mathrm{~cm}^{-3}\right)$ and negatively correlated at higher aerosol concentrations. They explained this behaviour by different phases of the cirrus lifecycle and accordingly cloud 


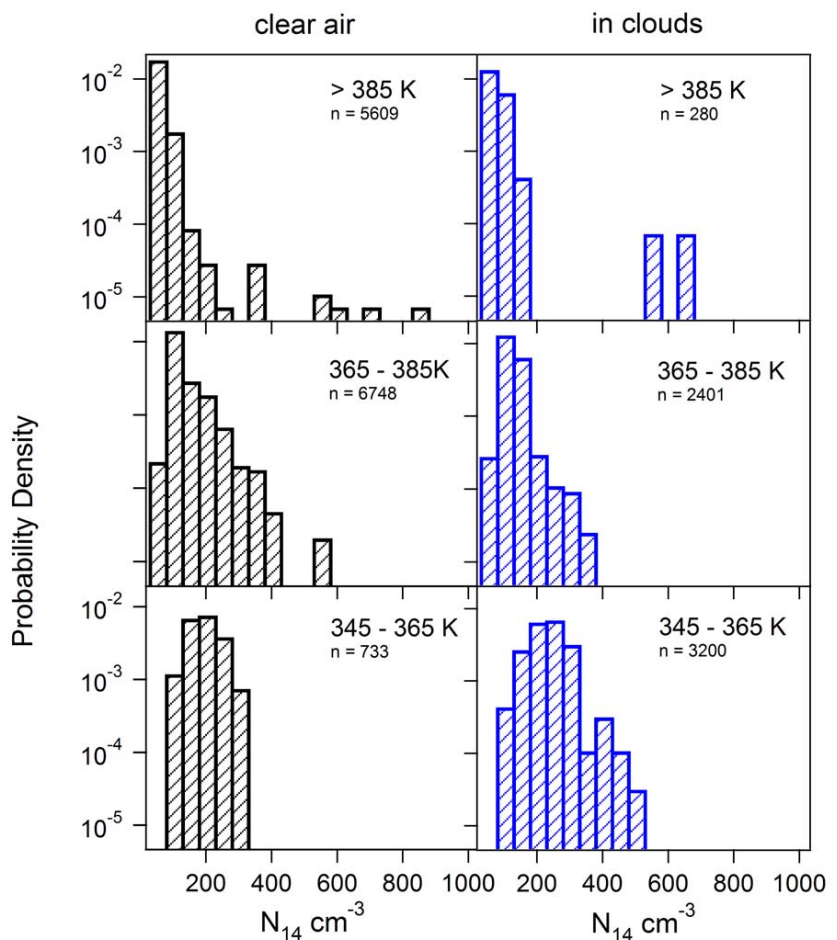

Fig. 9. Probability density functions of the total aerosol number concentration $\left(\mathrm{N}_{14}\right)$ in the stratosphere $(>385 \mathrm{~K})$, the upper troposphere $(365-385 \mathrm{~K})$ and the middle troposphere $(345-355 \mathrm{~K})$. The left panels show the distributions in clear air, the right panels within clouds. $\mathrm{N}$ presents the number of data points which are the basis of the probability density functions.

formation is associated with positive correlations, while the correlations are smaller or even negative in dissolving clouds. This theory, however, can not directly be translated to the SCOUT-O ${ }_{3}$ data in Fig. 10 because here averages of cloud events are shown and not the correlation within a single cirrus cloud. Despite the caveats discussed here the data presented in Fig. 10 are of interest for modelling purposes as they provide ranges of numbers actually observed in the complex environment of the tropical UT/LS.

\section{Discussion}

\subsection{Spatial extent of overshooting convection}

The effect of overshooting convection on the global stratospheric water budget is dependent on the frequency and the spatial scale of overshooting events. From the one event discussed in this paper it is impossible to make any statements about the frequency and average spatial scale of an overshooting event. That overshooting happens more regularly is shown by Corti et al. (2008), who report on overshooting convection events during 6 out of 16 flights in the tropical stratosphere over Australia and the South American

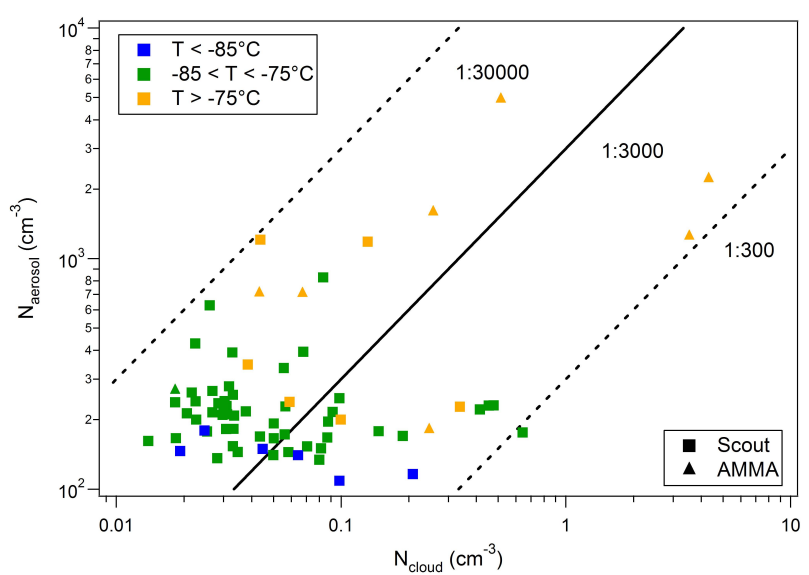

Fig. 10. Interstitial aerosol number concentration $\left(\mathrm{N}_{\text {aerosol }}\right)$ as function of the ice crystal number concentration $\left(\mathrm{N}_{\text {cloud }}\right)$ for three temperature ranges. The data points (squares) shown in this figure are averages over at least $30 \mathrm{~s}$ and correspond to the ice cloud encounters during the SCOUT-O ${ }_{3}$ campaign shown in Fig. 3. The triangles are ice cloud encounters at similar ambient temperatures during the AMMA-SCOUT-O 3 (African Monsoon Multidisciplinary Analyses) campaign over West Africa in August 2006

continent. However, it should be noted that the flight strategy during these campaigns was very much focussed on the investigation of potential overshoots.

Figure 5 shows the flight track of the discussed flight and the encounters with ice crystals in the stratosphere. The horizontal extent of the ice cloud is 0.27 degrees latitude and 0.36 longitude, corresponding to about $30 \mathrm{~km} \times 40 \mathrm{~km}$. Ice crystals were observed between 0.7 and $1.4 \mathrm{~km}$ above the tropopause, but not at $1.5 \mathrm{~km}$ above the tropical tropopause. Moreover, lidar measurements indicate that the ice crystals were observed down to the local tropopause (Fig. 6b). Hence, the spatial scale of this overshooting event is about $30 \times 40 \times 1.4 \mathrm{~km}$. Note, however, that the "cloud" structure is highly inhomogeneous, and not completely filled with ice crystals as suggested by the fact that, when flying at $18.8 \mathrm{~km}$ altitude, no ice particles were measured in between the different encounters with the ice clouds.

\subsection{Potential artefacts by shattering}

Ice crystal size distribution and number concentration measurements by microphysical probes such as the FSSP and CIP are currently the subject of intensive discussions, due to the potential shattering problem (Field et al., 2006; McFarquar et al., 2007; Heymsfield, 2007). Due to the high airspeed of the aircraft used for in-situ measurements, ice particles with sizes several hundred microns or larger can hit the forward surfaces of the probes, shatter and produce a large number of small particles. This causes an overestimation of the number concentration of small particles observed by, for example, the FSSP probe. The CIP data have been 
corrected for potential shattering events using the interarrival time method proposed by Field et al. (2006). This method assumes that the shattering of a large ice crystal causes a burst of small particles with very short interarrival times, which can be distinguished from the longer interarrival times of real cloud particles in a cirrus cloud (see Fig. 1b). Since information about the interarrival times of crystals observed by the FSSP probe is not available, we have investigated the shattering problem for our data set by comparing it to a data set which is not influenced by shattering as proposed by Heymsfield (2007). This data set, presented by McFarquar and Heymsfield (1997), has been the basis for a parameterisation for cirrus cloud size distributions using the temperature and total ice water content as input values. This parameterisation is valid for cirrus clouds in the outflow region of convective clouds, comparable to the ice clouds observed during this study. Using the observed IWC and temperature we calculated the IWC for the size ranges of the FSSP and CIP and compared this to the IWC measured by the two individual instruments (see Fig. 11). At low IWC both datasets show a similar distribution of the ice water content between the two observed size ranges, while at higher IWC the IWC measured by the FSSP is below the value predicted by the MH97 parameterisation. When shattering occurs the IWC for the FSSP size range should be overestimated, as has been shown by Heymsfield (2007). Despite the low ice water content measured by the FSSP, the linear relation between the $\operatorname{IWC}_{\mathrm{FSSP}}$ and the $\mathrm{IWC}_{\mathrm{CIP}}$ at higher IWC $\left(>10^{-4} \mathrm{~g} \mathrm{~m}^{-3}\right)$ might be an indication for the occurrence of shattering. To summarise, our dataset shows no indication for a severe shattering problem for IWC $<10^{-4} \mathrm{~g} \mathrm{~m}^{-3}$. At higher IWC we cannot exclude the occurrence of shattering although the discussion in Sect. 3.2 in connection with Fig. 4 indicates that the influence of shattering seems to be small.

\section{Summary and conclusions}

Large ice crystals, with sizes up to $400 \mu \mathrm{m}$ maximum dimension, have been observed in the tropical stratosphere, up to $1.4 \mathrm{~km}$ above the local tropopause, directly above the Hector cumulonimbus storm system. These particles have been transported into the stratosphere by overshooting convection and are remnants of a very fresh overshooting cumulonimbus cloud top. The ice water content of the stratospheric ice clouds ranged between $7.7 \times 10^{-5}$ and $8.5 \times 10^{-4} \mathrm{~g} \mathrm{~m}^{-3}$. The ice clouds were observed at ambient relative humidities (with respect to ice) between 75 and 157\%. Calculations of the evaporation rates and stratospheric residence times of the ice crystals show that they are likely to have humidified the stratosphere locally, although no estimate of the global significance could be made here.

In the tropical upper troposphere a decrease in effective radius was observed for ice clouds with altitude (or potential temperature) ranging from $100 \mu \mathrm{m}$ at about $10 \mathrm{~km}$ altitude to

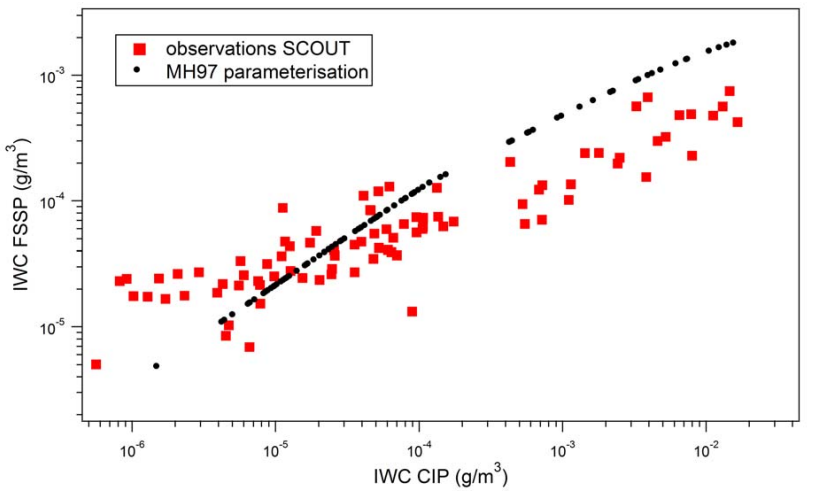

Fig. 11. Comparison of the ice water content measured by the FSSP and CIP instruments to the IWC for the same size ranges calculated using the parameterisation of McFarquar and Heymsfield (1997).

$3 \mu \mathrm{m}$ at the tropopause. This could also be represented by three modal lognormal size distributions fitted to the average observed size distribution at different potential temperature levels. The lognormal distributions show a decrease in mean mode diameter of all three modes when ascending towards the tropopause. The ice water content decreases accordingly from $0.04 \mathrm{~g} \mathrm{~m}^{-3}$ in the middle troposphere to $10^{-5} \mathrm{~g} \mathrm{~m}^{-3}$ close to the tropopause. No clear trend in the number concentration was observed with altitude, due to the thin and inhomogeneous characteristics of the observed cirrus clouds.

A large problem with in-situ ice crystal size distribution measurements is shattering of large ice crystals on the housing of the microphysical instruments. A comparison of the observed ice crystal distributions with a parameterisation by McFarquar and Heymsfield (1997) indicates that our dataset shows no indication for a severe shattering problem for IWC $<10^{-4} \mathrm{~g} \mathrm{~m}^{-3}$. At higher IWC we cannot exclude the occurrence of shattering although we believe that its influence is low. Moreover, a comparison of the ice water content calculated from the observed ice crystal size distribution with the ice water content derived from two hygrometer instruments shows a good agreement for ice water contents exceeding $2 \times 10^{-4} \mathrm{~g} \mathrm{~m}^{-3}$, which is also a good indication for the quality of the measurements and a low influence of shattering.

Probability density functions of the total aerosol number concentration in and out of clouds are presented. In the upper troposphere and stratosphere the total aerosol number concentration in and out of clouds show similar distributions, while in the middle troposphere higher aerosol concentrations within clouds were observed compared to clear air measurements. This could have been caused by the lack of outflow of the convective system at these altitudes.

Utilizing total aerosol number concentration measurements from a four channel condensation particle counter during two separate campaigns, it can be shown that the fraction of ice particles to the number of aerosol particles remaining 
ranges from 1:300 to 1:30 000 for tropical upper tropospheric ice clouds with ambient temperatures below $-75^{\circ} \mathrm{C}$.

We would like to emphasize that the performance of the measurements presented in this study and the collection of high quality data in the UT/LS by means of a specialised high altitude research aircraft under the conditions given by the Hector storm system is extremely difficult.

Acknowledgements. We thank Sebastian Raupach, Christian von Glahn and Hermann Vössing from the University of Mainz for carrying out the CIP and FSSP instrument preparation and data collection during the $\mathrm{SCOUT}-\mathrm{O}_{3}$ campaign. The SCOUT-O $\mathrm{O}_{3}$ project was funded by the European Commission (GOCE-CT2004-505390) and additional financial support was provided by the Max Planck Society and the Collaborative Research Centre "The Tropospheric Ice Phase" (SFB-641). The participation of Aaron Bansemer and Andrew Heymsfield to the SCOUT/ACTIVE project was funded by the University of Manchester. Special thanks to the entire "Geophysica" crew and the local authorities in Darwin (Australia) and Ouagadougou (Burkina Faso) for their excellent collaboration during the campaign. Many helpful comments from the participants of the Oral Session 5 on Cirrus Clouds during the 15th International Conference on Clouds and Precipitation, July 2008 in Cancun, Mexico are greatly appreciated as is the diligent handling of the manuscript by the editor Dominik Brunner.

The service charges for this open access publication have been covered by the Max Planck Society.

Edited by: D. Brunner

\section{References}

Baker, B. and Lawson, R. P.: Improvement in determination of ice water content from two-dimensional particle imagery, Part I: image to mass relationships, J. Appl. Meteorol. Clim., 45, 12821290, 2006.

Baumgardner, D, Dye, J. E., Gandrud, B. W., and Knollenberg, R. G.: Interpretation of measurements made by the forward scattering spectrometer probe (FSSP-300) during the airborne arctic stratospheric expedition, J. Geophys. Res., 97, 8035-8046, 1992.

Baumgardner, D. and Korolev, A.: Airspeed corrections for optical array probe sample volumes, J. Atmos. Ocean. Tech., 14, 12241229, 1997.

Borrmann, S., Solomon, S., Dye, J. E., and Luo, B.: The potential of cirrus clouds for heterogeneous chlorine activation, Geophys. Res. Lett., 23, 2133-2136, 1996.

Borrmann, S., Luo, B., and Mishchenko, M.: The application of the T-matrix method to the measurement of aspherical particles with forward scattering optical particle counters, J. Aerosol Sci., 31, 789-799, 2000.

Brunner, D., Siegmund, P., May, P. T., Chappel, L., Schiller, C., Müller, R., Peter, T., Fueglistaler, S., MacKenzie, A. R., Fix, A., Schlager, H., Allen, G., Fjaeraa, A. M., Streibel, M., and Harris, N. R. P.: The SCOUT-O 3 Darwin Aircraft Campaign: rationale and meteorology, Atmos. Chem. Phys., 9, 93-117, 2009, http://www.atmos-chem-phys.net/9/93/2009/.

Chaboureau, J.-P., Cammas, J.-P., Duron, J., Mascart, P. J., Sitnikov, N. M., and Voessing, H.-J.: A numerical study of tropical cross-tropopause transport by convective overshoots, Atmos. Chem. Phys., 7, 1731-1740, 2007,

http://www.atmos-chem-phys.net/7/1731/2007/.

Chen, J. P., McFarquhar, G. M., Heymsfield, A. J., and Ramanathan, A. J..: A modelling and observational study of the detailed microphysical structure of tropical cirrus anvils, J. Geophys. Res., 102, 6637-6653, 1997.

Connolly, P. J., Choularton, T. W., Gallagher, M. W., Bower, K. N., Flynn, M. J., and Whiteway, J. A.: Cloud-resolving simulations of intense tropical Hector thunderstorms: Implications for aerosol-cloud interactions, Q. J. Roy. Meteorol. Soc., 132, 30793106, 2006.

Corti, T., Luo, B. P., de Reus, M., Brunner, D., Cairo, F., Mahoney, M. J., Martucci, G., Matthey, R., Mitev, V., dos Santos, F. H., Schiller, C., Shur, G., Sitnikov, N. M., Spelten, N., Vössing, H. J., Borrmann, S., and Peter, T.: Unprecedented evidence for overshooting convection hydrating the tropical stratosphere, Geophys. Res. Lett., 35, L10810, doi:10.1029/2008GL033641, 2008.

Curtius, J., Weigel, R., Vössing, H.-J., Wernli, H., Werner, A., Volk, C.-M., Konopka, P., Krebsbach, M., Schiller, C., Roiger, A., Schlager, H., Dreiling, V., and Borrmann, S.: Observations of meteoric material and implications for aerosol nucleation in the winter Arctic lower stratosphere derived from in situ particle measurements, Atmos. Chem. Phys., 5, 3053-3069, 2005, http://www.atmos-chem-phys.net/5/3053/2005/.

Curtius, J.: Nucleation of atmospheric aerosol particles, C. R. Physique, 7, 1027-1045, 2006.

de Reus, M., Krejci, R., Williams, J., Fischer, H., Scheele, R., and Ström, J.: Vertical and horizontal distributions of the aerosol number concentration and size distribution over the northern Indian Ocean, J. Geophys. Res., 106, 28629-28641, 2001.

Dye, J. E. and Baumgardner, D.: Evaluation of the Forward Scattering Spectrometer Probe, Part I: Electronic and optical studies, J. Atmos. Ocean. Tech., 1, 329-344, 1984.

Eremenko, M. N., Zasetsky, A. Y., Boone, C. D., and Sloan, J. J.: Properties of high-altitude tropical cirrus clouds determined from ACE FTS observations, Geophys. Res. Lett., 32, L15S07, doi:10.1029/2005GL022428, 2005.

Field, P. R., Heymsfield, A. J., and Bansemer, A.: Shattering and particle interarrival times measured by optical array probes in ice clouds, J. Atmos. Ocean. Tech., 23, 1357-1371, 2006.

Garrett, T. J., Gerber, H., Baumgardner, D. G., Twohy, C. H., and Weinstock, E. M.: Small, highly reflective ice crystals in low-latitude cirrus, Geophys. Res. Lett., 30, 2132, doi:10.1029/2003GL018153, 2003.

Garrett, T. J., Dean-Day, J., Liu, C., Barnett, B., Mace, G., Baumgardner, D., Webster, C., Bui, T., Read, W., and Minnis, P.: Convective formation of pileus cloud near the tropopause, Atmos. Chem. Phys., 6, 1185-1200, 2006, http://www.atmos-chem-phys.net/6/1185/2006/.

Gayet, J. F., Ovarlez, J., Shcherbakov, V., Ström, J., Schumann, U., Minikin, A., Auriol, F., Petzold, A., and Monier, M.: Cirrus cloud microphysical and optical properties at southern and northern midlatitutes during the INCA Experiment, J. Geophys. Res., 109, D20206, doi:10.1029/2004JD004803, 2004.

Grosvenor, D. P., Choularton, T. W., Coe, H., and Held, G.: A study of the effect of overshooting deep convection on the water content of the TTL and lower stratosphere from Cloud Resolving 
Model simulations, Atmos. Chem. Phys., 7, 4977-5002, 2007, http://www.atmos-chem-phys.net/7/4977/2007/.

Heymsfield, A. J., and Parrish, J. L.: A computational technique for increasing the effective sampling volume of the PMS two-dimensional particle size spectrometer, J. Appl. Meteorol., 17, 1566-1572, 1978.

Heymsfield, A. J.: Ice particles observed in a cirriform cloud at $-83^{\circ} \mathrm{C}$ and implications for polar stratospheric clouds, J. Atmos. Sci., 43, 851-855, 1986.

Heymsfield, A. J. and McFarquhar, G. M.: Midlatitude and tropical cirrus - microphysical properties, in: Cirrus, edited by: Lynch, D. K., Sassen, K., Starr, D. O., and Stephens, G., Oxford Univ. Press, New York, 2002.

Heymsfield, A. J., Schmidt, C., Bansemer, A., van Zadelhoff, G. J., McGill, M. J., Twohy, M. J., and Baumgardner, D.: Effective radius of ice cloud particle populations derived from aircraft probes, J. Atmos. Ocean. Tech., 23, 361-380, 2006.

Heymsfield, A. J.: On measurements of small ice particles in clouds, Geophys. Res. Lett., 34, L23812, doi:10.1029/2007GL030951, 2007.

Kärcher, B. and Lohmann, U.: A parameterization of cirrus cloud formation: Homogeneous freezing of supercooled aerosols, J. Geophys. Res., 107, 4010, doi:10.1029/2001JD000470, 2002.

Knollenberg, R. G.: The optical array: an alternative to scattering or extinction for airborne particle size determination, J. Appl. Meteorol., 9, 86-103, 1970.

Knollenberg, R. G., Kelly, K., and Wilson, J. C.: Measurements of high number densities of ice crystals in the tops of tropical cumulonimbus, J. Geophys. Res., 98, 8639-8664, 1993.

Korolev, A. V., Strapp, J. W., and Isaac, G. A.: Evaluation of the accuracy of PMS Optical Array Probes, J. Atmos. Ocean. Tech., 15, 708-720, 1998.

Korolev, A.: Reconstruction of the sizes of spherical particles from their shadow images, Part I: Theoretical considerations, J. Atmos. Ocean. Tech., 24, 376-389, 2007.

Krämer, M., and Afchine, A.: Sampling characteristics of inlets operated at low U/U0 ratios: new insights from computational fluid dynamics (CFX) modeling, J. Aerosol Sci., 35, 683-694, doi:10.1016/j.jaerosci.2003.11.011, 2004.

Krämer, M., Schiller, C., Afchine, A., Bauer, R., Gensch, I., Mangold, A., Schlicht, S., Spelten, N., Sitnikov, N., Borrmann, S., de Reus, M., and Spichtinger, P.: Ice supersaturations and cirrus cloud crystal numbers, Atmos. Chem. Phys., 9, 3505-3522, 2009 , http://www.atmos-chem-phys.net/9/3505/2009/.

Lee, S. H., Wilson, J. C., Baumgardner, D., Herman, R. L., Weinstock, E. M., LaFleur, B. G., Kok, G., Anderson, B., Lawson, P., Baker, B., Strawa, A., Pittman, J. V., Reeves, J. M., and Bui, T. P.: New particle formation observed in the tropical/subtropical cirrus clouds, J. Geophys. Res., 109, D20209, doi:10.1029/2004JD005033, 2004.

Lynch, D. K., Sassen, K., Starr, D. O., and Stephens, G.: Cirrus, Oxford Univ. Press, New York, 2002.

McFarquhar, G. M. and Heymsfield, A. J.: Parameterisation of tropical cirrus ice crystal size distributions and implications for radiative transfer: results from CEPEX, J. Atmos. Sci., 54, 21872200, 1997.

McFarquhar, G. M. and Heymsfield, A. J.: The definition and significance of an effective radius for ice clouds, J. Atmos. Sci., 55,
2039-2052, 1998.

McFarquhar, G. M., Heymsfield, A. J., Spinhirne, J., and Hart, B.: Thin and subvisual tropopause tropical cirrus: observations and radiative impacts, J. Atmos. Sci., 57, 1841-1853, 2000.

McFarquhar, G. M., Um, J., Freer, M., Baumgardner, D., Kok, G. L., and Mace, G.: Importance of small ice crystals to cirrus properties: Observations from the tropical warm pool international cloud experiment (TWP-ICE), Geophys. Res. Lett., 34, L13803, doi:10.1029/2007GL029865, 2007.

Mitchell, D. L. and Heymsfield, A. J.: Refinements in the Treatment of ice particle terminal velocities, highlighting aggregates, J. Atmos. Sci., 62, 1637-1644, 2005.

Mitev, V., Matthey, R., and Makanov, V.: Miniature backscatter lidar for cloud and aerosol observation from high altitude aircraft, Rec. Res. Dev. Geophys., 4, 207-223, 2002.

Nielsen, J. K., Larsen, N., Cairo, F., Di Donfrancesco, G., Rosen, J. M., Durry, G., Held, G., and Pommereau, J. P.: Solid particles in the tropical lowest stratosphere, Atmos. Chem. Phys., 7, 685695, 2007, http://www.atmos-chem-phys.net/7/685/2007/.

Oltmans, S. J., Vömel, H., Hofmann, D. J., Rosenlof, K. H., and Kley, D.: The increase in stratospheric water vapour from balloonborne, frostpoint hygrometer measurements at Washington D.C. and Boulder, Geophys. Res. Lett., 27, 3453-3456, 2000.

Peter, Th., Luo, B. P., Wirth, M., Kiemle, C., Flentje, H., Yushkov, V. A., Khattatov, V., Rudakov, V., Thomas, A., Borrmann, S., Toci, G., Mazzinghi, P., Beuermann, J., Schiller, C., Cairo, F., Di Donfrancesco, G., Adriani, A., Volk, C. M., Strom, J., Noone, K., Mitev, V., MacKenzie, R. A., Carslaw, K. S., Trautmann, T., Santacesaria, V., and Stefanutti, L.: Ultrathin Tropical Tropopause Clouds (UTTCs): I, Cloud morphology and occurrence, Atmos. Chem. Phys., 3, 1083-1091, 2003, http://www.atmos-chem-phys.net/3/1083/2003/.

Pratte, P., van den Bergh, H., and Rossi, M. J.: The kinetics of $\mathrm{H}_{2} \mathrm{O}$ vapor condensation and evaporation on different types of ice in the range 130-210 K, J. Phys. Chem. A, 110, 3042-3058, 2006.

Schiller, C., Krämer, M., Afchine, A., Spelten, N., and Sitnikov, N.: The ice water content of Arctic, mid latitude and tropical cirrus, J. Geophys. Res., 113, D24208, doi:10.1029/2008JD010342, 2008.

Schröder, F., Kärcher, B., Duroure, C., Ström, J., Petzold, A., Gayet, J. F., Strauss, B., Wendling, P., and Borrmann, S.: On the transition of contrails into cirrus clouds, J. Atmos. Sci., 57, 464-480, 2000.

Seifert, M., Ström, J., Krejci, R., Minikin, A., Petzold, A., Gayet, J.-F., Schlager, H., Ziereis, H., Schumann, U., and Ovarlez, J.: Aerosol-cirrus interactions: a number based phenomenon at all?, Atmos. Chem. Phys., 4, 293-305, 2004, http://www.atmos-chem-phys.net/4/293/2004/.

Seinfeld, J. H. and Pandis, S. N.: Atmospheric chemistry and physics: from air pollution to climate change, John Wiley and Sons, Hoboken, NJ, 2006.

Sherwood, S. C. and Dessler, A. E.: A Model for transport across the tropical tropopause, J. Atmos. Sci., 58, 765-779, 2001.

Sitnikov, N. M., Yushkov, V. A., Afchine, A. A., Korshunov, L. I., Astakov, V. I., Ulanovskii, A. E., Krämer, M., Mangold, A., Schiller, C., and Ravegnani, F.: The FLASH instrument for water vapor measurements on board the high altitude airplane, Instruments and Experimental Techniques, 50, 113-121, 2007. 
Solomon, S., Borrmann, S., Garcia, R. R., Portmann, R., Thomason, L., Poole, L. R., Winkler, D., and McCormick, M. P.: Heterogeneous chlorine chemistry in the tropopause region, J. Geophys. Res., 102, 21411-21429, 1997.

Stephens, G. L. and Webster, P. J.: Clouds and climate: sensitivity of simple systems, J. Atmos. Sci., 38, 235-247, 1981.

Strapp, J. W., Albers, F., Reuter, A., Korolev, A. V., Maixner, U., Rashke, E., and Vukovic, Z.: Laboratory measurements of the response of a PMS OAP-2DC, J. Atmos. Ocean. Tech., 18, 11501170, 2001.

Ström, J., Strauss, B., Anderson, T., Schröder, F., Heintzenberg, J., and Wendling, P.: In-situ observations of the microphysical properties of young cirrus clouds, J. Atmos. Sci., 54, 2542-2553, 1997.

Thomas, A., Borrmann, S., Kiemle, C., Cairo, F., Volk, M., Beuermann, J., Lepuchov, B., Santacesaria, V., Matthey, R., Rudakov, V., Yushkov, V., MacKenzie, A. R., and Stefanutti, L.: In-situ measurements of background aerosol and subvisible cirrus in the tropical tropopause region, J. Geophys. Res., 107, 4763, doi:10.1029/2001JD001385, 2002.

Vaughan, G., Schiller, C., MacKenzie, A. R., Bower, K., Peter, T., Schlager, H., Harris, N. R. P., and May, P. T.: SCOUT$\mathrm{O}_{3}$ /ACTIVE high-altitude aircraft measurements around deep tropical convection, B. Am. Meteorol. Soc., 89, 647-662, 2008.
Voigt, C., Schlager, H., Ziereis, H., Kärcher, B., Luo, B. P., Schiller, C., Krämer, M., Popp, P. J., Irie, H., and Kondo, Y.: Nitric acid uptake in cirrus clouds, Geophys. Res. Lett., 33, L05803, doi:10.1029/2005GL025159, 2006.

Weigel, R., Hermann, M., Curtius, J., Voigt, C., Walter, S., Böttger, T., Lepukhov, B., Belyaev, G., and Borrmann, S.: Experimental characterization of the COndensation PArticle counting System for high altitude aircraft-borne application, Atmos. Meas. Tech., 2, 243-258, 2009, http://www.atmos-meas-tech.net/2/243/2009/.

Yushkov, V., Oulanovsky, A., Lechenuk, N., Roudakov, I., Arshinov, K., Tikhonov, F., Stefanutti, L., Ravegnani, F., Bonafe, U., and Georgiadis, T.: A chemiluminescent analyzer for stratospheric measurements of the ozone concentration (FOZAN), J. Atmos. Ocean. Tech., 16, 1345-1350, 1999.

Zöger, M., Afchine, A., Eicke, N., Gerhards, M. T., Klein, E., McKenna, D. S., Mörschel, U., Schmidt, U., Tan, V., Tuitjer, F., Woyke, T., and Schiller, C.: Fast in-situ stratospheric hygrometers: A new family of balloonborne and airborne Lyman- $\alpha$ photofragment fluorescence hygrometers, J. Geophys. Res., 104, 1807-1816, 1999. 